\title{
Redes territoriales: relaciones de crianza kichwa lamista y San Martín como «región verde»
}

\author{
Anahí Chaparro \\ (iD) https://doi.org/0000-0001-7321-4307 \\ Universidad Federal de Río de Janeiro \\ Centro Amazónico de Antropología y Aplicación Práctica \\ anahichaparro@gmail.com
}

RESUMEN

Este artículo plantea un ejercicio de antropología simétrica, siguiendo los caminos propuestos por Latour (1994), al comparar dos redes - no desconectadas entre sí- articuladas por distintas formas de conocer: la de las relaciones que constituyen el territorio de «San Martín, región verde» y la de las relaciones de crianza de los kichwa lamista, partiendo de la comunidad de Alto Pucalpillo. El interés de este artículo es aproximarnos a los vínculos que este conocer activa a través de sus efectos, a sus modos de constituir sujetos y de producir el territorio. Por un lado, el entrelazamiento entre humanos, plantas, animales y otros seres que comparten el mismo entorno, como sujetos con agencia, afectos y voluntad propia, conforma una red de cuidados, no exenta de tensiones. Por el otro, la red de actores que participan en la conservación de la «región verde» se relaciona con el territorio en tanto realidad objetiva de la cual puede extraer una verdad. A partir de un conocimiento técnico-científico que concibe como neutral, crea mapas que definen fronteras en el espacio y entre lo legal y lo ilegal, al mismo tiempo que cuestiona la condición de las comunidades nativas como sujetos de derecho. Con ello, no se pretende afirmar que entre ambas redes no existan puntos de encuentro, sino la necesidad de encaminar una coexistencia nutritiva.

Palabras clave: redes, territorio, kichwa, San Martín, conocer, crianza 


\section{Territorial networks: Kichwa Lamista nurture relationships and San Martín as «región verde»}

ABSTRACT

This article presents an exercise of symmetric anthropology, following the paths proposed by Latour (1994), comparing two networks - not disconnected from each other - that are linked by different ways of knowing: that of the relationships that constitute the territory of «San Martin, región verde» and that of the Kichwa Lamista nurture relationships, departing from Alto Pucalpillo community. The interest of this article is to approach the bonds that this knowledge activates through its effects, its ways of constituting subjects and producing the territory. On one hand, the intertwining between humans, plants, animals and other beings that share the same environment, as subjects with agency, affections and their own will, forms a network of care, not without tension. On the other hand, the network of actors that participate in the conservation of the "green region" relates to the territory as an objective reality from which it can extract a truth. From a technical-scientific knowledge conceived as neutral, they create maps that define borders in space and between what is legal and what is illegal, at the same time that they question the condition of native communities as subjects of rights. With this, the author does not intend to affirm that there aren't intersections between de two networks, but rather the need to direct ourselves towards a nutritive coexistence.

Keywords: networks, territory, Kichwa, San Martin, knowing, nurture 


\section{INTRODUCCIÓN ${ }^{1}$}

Este artículo plantea un ejercicio de antropología simétrica, siguiendo los caminos propuestos por Latour (1994), al comparar dos redes — no desconectadas entre sí- articuladas por distintas formas de conocer: la de las relaciones que constituyen el territorio de «San Martín, región verde» y la de las relaciones de crianza (wiway) de los kichwa lamista, partiendo de la comunidad de Alto Pucalpillo. El interés de este artículo es aproximarnos a los vínculos que estas formas de conocer activan, a través de sus efectos, a sus modos de constituir sujetos y de producir el territorio que se extiende, principalmente, por las cuencas de los ríos Mayo y Huallaga, al norte del Perú, en la Amazonía Occidental

Para abordar las relaciones de crianza de los kichwa lamista, retomo los trabajos sobre los pueblos indígenas amazónicos que enfatizan la inseparabilidad del cuerpo y el conocimiento de Kensinger (1995) y McCallum (1996) a partir de su investigación con los huni-kui. Estas reflexiones se alimentan de los estudios antropológicos de las tierras bajas sudamericanas que, desde Da Matta (1976), Overing (1977), Seeger, Da Matta y Viveiros de Castro (1979) y Viveiros de Castro

\footnotetext{
Esta reflexión parte de mi experiencia anterior con los kichwa en San Martín. Entre 2013 y 2016, y entre 2018 y 2019, trabajé en una organización no gubernamental (el Centro Amazónico de Antropología y Aplicación Práctica) en un proyecto, con el objetivo de acompañar a las organizaciones y comunidades indígenas en la defensa de sus derechos territoriales. Asimismo, retoma mi investigación de maestría junto a las personas de Alto Pucalpillo sobre su sentido de caminar (puriy) y el vínculo con sus relaciones de crianza (wiway) frente a las fronteras que interrumpen su flujo (Chaparro, 2018). Esta investigación fue posible gracias a la beca Nota 10 de la Fundação Carlos Chagas Filho de Amparo à Pesquisa do Estado do Rio de Janeiro. Agradezco a las profesoras que me acompañaron en este proceso. A mi asesora, Eliane O'Dywer, mi coasesora, Deborah Bronz, y a Luisa Elvira Belaúnde. Asimismo, a los que participaron como jurados en mi sustentación, Oiara Bonilla y Edmundo Pereira, y a los evaluadores ciegos del artículo que contribuyeron con valiosos comentarios. Finalmente, agradezco a mis compañeros de trabajo de las distintas instituciones, organizaciones indígenas y comunidades kichwa con los que compartimos los caminos aquí descritos. En especial, a todas las personas de la comunidad de Alto Pucalpillo, que me acogieron con gran generosidad. Los posibles errores u omisiones son de mi entera responsabilidad.
} 
(1979), reconocen la importancia de la alimentación y la manipulación de los fluidos corporales como modos de consubstancialización en el proceso continuo de constitución de las personas y reproducción del parentesco, en contraposición a una noción de parentesco biológico definido en la concepción y el nacimiento. En estas investigaciones, la apropiación e incorporación -o la predación y la familiarización, siguiendo la propuesta de Fausto (2002)- de la alteridad de otros seres (humanos, animales, plantas y otros) ocupa un papel central. Aunque con diferentes matices - relacionados también con las diferencias entre los distintos pueblos (ver Descola, 1998) — estas permiten percibir cómo las relaciones de los humanos con los no humanos, sea de los chamanes con sus espíritus ayudantes, de los cazadores con sus presas o de los hombres y mujeres con sus plantas o animales domésticos, entre otros, también pueden entenderse como parte de las relaciones de parentesco o crianza. En este sentido, investigaciones recientes, que retoman contribuciones tanto de la antropología como de la arqueología (como Fausto y Neves, 2018, y Carneiro da Cunha, 2020), enfatizan la familiarización de plantas y animales - no la domesticación, vincula a las nociones de control y dominación de un otro (animal o planta) como agente pasivo - como modo de relación que ha constituido el paisaje amazónico. Entre los kichwa lamista, como entre otros pueblos amazónicos, esta familiarización pasa por compartir alimentos y otras señales corporales, como el olor y la temperatura.

Este artículo, en diálogo con los autores que discuten la estética de la convivialidad en distintos pueblos amazónicos como la que describen en la introducción de su libro compilatorio Overing y Passes (2000), plantea una reflexión sobre cómo la crianza de los parientes y la familiarización de los otros en las comunidades kichwa lamista pasan por desarrollar el querer, vinculado con la formación de cuerpos semejantes y el deseo de crecer juntos. Desde esta perspectiva, también se enfatiza cómo el conocimiento y su transmisión están insertos en relaciones de intimidad que implican el reconocimiento del otro en tanto sujeto semejante, aunque no igual.

Asimismo, este artículo explora la relación entre cuerpo y territorio a partir de las diferentes formas en que las personas de la comunidad kichwa de Alto Pucalpillo y los lugares que habitan se constituyen mutuamente. En este sentido, retomo las reflexiones de Gow (1995), a partir de su trabajo con los yine del Bajo Urubamba. Según este autor, las personas no solo otorgan un significado al paisaje. Sus vidas estás íntimamente ligadas a él en tanto este tiene una participación activa en la constitución de las personas y sus relaciones a través de la consubstancialización que produce el cuidado mutuo que permite su crecimiento 
y reproducción. Así, para Gow, tanto las prácticas de cultivo y regeneración del bosque como las narrativas míticas y la curación con plantas medicinales forman parte de las acciones significativas a partir de las cuales las personas y su entorno están involucrados entre sí. Esta reflexión se condice con la de Echeverri sobre cómo los territorios indígenas pueden ser concebidos como cuerpos que se alimentan, se reproducen y tejen relaciones con otros cuerpos (2004, p. 263).

Como se desarrolla a lo largo de este artículo, el territorio habitado por los kichwa lamista no está constituido por un espacio continuo, como presupone la normativa sobre la categoría jurídica de comunidades nativas. Tampoco abarca zonas de uso distribuidas en círculos concéntricos — con la casa colectiva y huertos al centro, rodeados por zonas de cultivo, caza y recolección cotidiana y, luego, de expediciones de largas distancias - como se pensó el uso del espacio por los indígenas amazónicos desde la antropología, según señalan Albert y Le Tourneau (2007) a partir de su experiencia con los yanomami. En lugar de eso, puede ser descrito, siguiendo a estos autores, como un «espacio reticular» conformado por diferentes caminos familiares que articulan lugares interconectados también con otras redes de caminos.

La población que se identifica, hoy en día, como kichwa lamista o de Lamas - antes, también, se autodenominaban Lamas runa (gente de Lamas) o Jakwashestá conformada por familias que proceden de esta ciudad, específicamente del Wayku, como se denomina a su parte baja. Algunas mantienen una casa ahí, donde regresan, esporádicamente, los fines de semana y, principalmente, para la fiesta de Santa Rosa. Actualmente, las familias lamista practican una forma de residencia multilocalizada caracterizada por un desplazamiento constante entre sus pueblos, los de sus parientes, Lamas, sus chacras y sus lugares de caza, pesca y recolección.

Lamas fue el mayor centro colonial donde se concentraron distintos grupos indígenas del río Mayo y de la parte media y baja del río Huallaga. Los kichwa de Lamas, dependiendo del contexto, pueden diferenciarse de otros kichwa de la región San Martín vinculados con otros antiguos centros coloniales, como los de Sisa o los del Huallaga. Sus caminos abarcan diferentes microclimas, tipos de tierra, y recorren montañas accidentadas entre los 400 y 2500 metros sobre el nivel del mar.

Los lamista continúan movilizándose pese a los intentos por sedentarizarlos en espacios reducidos. En las últimas décadas, se han visto desplazados de las partes bajas de las cuencas debido al aumento exponencial de la inmigración desde los Andes desde la construcción de la carretera Fernando Belaunde Terry, que en 
muchos casos produjo enfrentamientos violentos. La apertura de vías facilitó, durante las décadas de 1980 y 1990, la expansión del cultivo de coca y el incremento del narcotráfico, vinculado con el Movimiento Revolucionario Túpac Amaru, y actualmente, el tráfico de tierras, relacionado con el cultivo de palma aceitera.

Con el fin de frenar las altas tasas de deforestación generadas por el contexto descrito, en los últimos quince años se implementó en la región una serie de políticas ambiental que, entre otras estrategias, incluyó la creación de áreas de conservación que han criminalizado las actividades de los pueblos indígenas (Chaparro y Valderrama, 2017; Chaparro, 2018). La que ha tenido mayor impacto en la vida de los kichwa lamista es el área de conservación regional Cordillera Escalera, creada en 2005 sin cumplir con la consulta previa, libre e informada. En 2010, ocho personas de la comunidad de Alto Pucalpillo fueron enjuiciadas por realizar labores agrícolas dentro esta área. A pesar de no ser sentenciados como culpables, al dictaminar que fue un «error culturalmente condicionado» fueron coaccionadas a abandonar sus cultivos. Posteriormente, personas de otras comunidades kichwa han sido denunciadas por los mismos motivos.

Al mismo tiempo, la disminución de las tasas de deforestación, las mejoras de los indicadores socioeconómicos y la incorporación de un enfoque territorial convirtieron a San Martín en un referente de buena gestión pública en el Perú. Esto nos lleva a reflexionar sobre los valores que están en juego en las concepciones de desarrollo y bienestar. Por ello, en la segunda sección, me enfoco en cómo se ha constituido la «región verde» y en a las comunidades nativas como sujetos de derecho en la práctica, en los últimos años, marcados por las políticas de desarrollo sostenible en San Martín. Retomando la reflexión sobre la antropología del desarrollo que plantea Ferguson (2012) a partir de los aportes de Foucault $(1979,1989)$, consideró a este como una experiencia histórica singular que se ha constituido como aparato de saber-poder desde la segunda mitad del siglo XX, funcionando como valor central a partir del cual se evalúa la eficiencia de los gobiernos y se caracteriza a las poblaciones (Escobar, 2007[1998]; Ferguson, 2012). Al apellidarlo sostenible, como señala Sachs (2000), se ha sumado la configuración del medio ambiente como un problema global y la consolidación de la gestión internacional de los recursos naturales como técnica de gobierno.

En este sentido, me interesa mostrar los efectos que ha tenido, en San Martín, este régimen de verdad, principalmente a partir de la Zonificación Ecológica Económica, que ha definido los territorios a partir de su «vocación» y a la población indígena como dominios de conocimiento, campos de intervención y como objetos y sujetos del desarrollo sostenible, en tanto son constituidos por este al mismo 
tiempo que contribuyen a su formación. Para a ello, me inspiro en las reflexiones de Echeverri (2004) sobre la creación de áreas naturales protegidas en territorios indígenas en Colombia, quien contrapone el enfoque de «zonificación de áreas geográficas» que prima en los instrumentos de gestión ambiental —en el que cada área se define a partir de la identificación de atributos pensados como preexistentes- a la noción de «territorio no aureolar» concebido como un cuerpo.

Así, propongo reflexionar sobre cómo la construcción de técnicas para la gestión territorial despolitiza a la naturaleza al definirla como recursos naturales a ser gestionados y posicionar un conocimiento técnico-científico como el único válido para decidir sobre ellos. También retomo las reflexiones de Foucault (1979), que vinculan las formas de conocimiento, las estrategias de poder y las tecnologías del self para pensar sobre las formas de autogobierno a partir de las cuales los sujetos, en su condición de seres libres, se constituyen a sí mismos como individuos éticos según la racionalidad imperante. En este caso, las comunidades nativas pasan a definirse como sujetos de derechos colectivos responsables por la conservación. Como apunta Segato (2014), es posible pensar el avance del mercado global y del discurso de derechos ciudadanos como dos caras del mismo proceso de colonización del capitalismo contemporáneo, sin querer desconocer con ello - como señala Escobar (2010) para el caso colombiano - las posibilidades de agencia que se abren con la configuración de sujetos políticos a partir de los nuevos órdenes de construcción de la diferencia.

\section{LA RED DE CRIANZA KICHWA LAMISTA}

\subsection{Crianza de los cuerpos-temperamentos humanos}

En Alto Pucalpillo, la crianza de los hijos, desde su formación en el útero, implica una serie de cuidados y acompañamientos para formar su cuerpo y carácter - los cuales no son entendidos como aspectos diferenciados-, como para que sean sinchikuna (duros y fuertes) y trabajadores, no perezosos ni dormilones. Así, mediante las relaciones sexuales, la alimentación y las actividades de ambos padres, algunos elementos del ambiente son evitados, mientras que otros son transmitidos. Esto implica restricciones de algunas sustancias y actividades, en tanto que otras son priorizadas y otras moduladas antes, durante y después del parto. Por ejemplo, según doña Jesús Guerra Cachique, un bebé es llamado caiguachito cuando nace bien tranquilo debido a que la madre comió mucha caigua - abundante en las huertas de la comunidad — cuando estaba embarazada. 
El embarazo de la mujer también afecta a la chacra. Según los testimonios recogidos por Faiffer y Belaúnde (2016, p. 77), las mujeres embarazadas no pueden participar en la cosecha porque las plantas se pueden secar, ni entrar en una chacra con frijoles porque estos se malogran.

Hoy en día, los partos en casa son poco frecuentes debido al temor de las parteras de ser denunciadas por el personal de los hospitales en caso de complicaciones y a los gastos adicionales para la emisión del certificado de nacimiento, que las madres entienden como multas. Debido a ello, no se suele recuperar la placenta. Cuando el parto es realizado en casa, esta puede ser enterrada en varios lugares vinculados con la familia: en la chacra, el cementerio, una tierra pantanosa o húmeda cerca de la casa - elemento intermedio entre el agua y el monte, según Scazzocchio (1979, p. 268) - la casa de las hormigas — para que sea caminante y fuerte como una hormiga - o del armadillo (Tapullima, 2012; Faiffer y Belaúnde, 2016). Según afirma don Custodio Sangama Sangama:

La placenta del llullito [bebito] se entierra en las partes húmedas de la tierra más conocidas por nosotros, como los fangales, en el ishpanero de la casa, debajo del árbol del indano [árbol medicinal], esto para que nuestros hijos sean reconocidos y cuidados por las ánimas del monte, del agua y de la chacra (Tapullima, 2012, p. 305, mi resaltado).

Estos cuidados continúan después del nacimiento mediante ciertas dietas (que implican la ingestión, baños y/o frotaciones con preparados de plantas, raíces y/o cortezas junto a una serie de restricciones alimentarias y sexuales) que tienen que cumplir la madre y el padre. También le convidan al bebé remedios vegetales y se realizan otros tratamientos corporales. Según don Purificación Cachique Tuanama, a los varones se les ata un hilo en la muñeca con una semilla para que sean buenos leñadores o con un hueso de añuje para que sean bueno montaraces (Waman Wasi, 2015). En este sentido, para los lamista - así como para otros pueblos amazónicos, como señalan Kensinger (1995) y McCallum (1996), a partir de una reflexión sobre la epistemología kaxinawá - no es posible desligar el conocimiento del cuerpo.

Mientras van creciendo, los niños asumen progresivamente algunas responsabilidades. Cuando son adultos, el modelamiento del cuerpo, del carácter y de los afectos continúa a través de la ingestión o baños de plantas medicinales y en el cuidado del uso de la fuerza. Dentro de las dietas que realizan quienes se quieren convertir en médicos, cada purga afecta de una forma diferente. Don Rister Tangoa Pisco, de la comunidad nativa de Tununtunumba, en el Bajo 
Huallaga, describe la incorporación del conocimiento de las plantas como parte de un proceso de familiarización:

[El monte y el agua] escogen a la persona a quien dejar su sabiduría de sanación, porque ellos también quieren seguir conversando con los humanos [...]. A veces los humanos queremos ser curanderos a la fuerza, pero si el monte y el agua no te reconocen parte de su familia... Ellos también están muy preocupados por la comunidad humana (Waman Wasi, 2013, p. 77, mi resaltado).

Por su parte, según cómo se expresan en Alto Pucalpillo, los hijos crían también a sus padres cuando son mayores, principalmente los que se quedan viviendo en la misma casa. Estas relaciones de cuidado mutuo también incluyen la de los abuelos con los nietos, como en el caso de los wiwachos, término que puede traducirse como «criado». De la misma manera, también buscan acostumbrar a aquellas personas con quienes desean convivir, como a las mujeres afines, ya que la residencia suele ser patrilocal. Acostumbrar es un término usado también para referirse a la familiarización de otros seres, como se detalla más adelante.

Las relaciones de crianza se vuelven recíprocas a partir de la memoria de los cuidados recibidos ${ }^{2}$. Es a partir del cariño y de hacer las cosas con gusto que la familia se mantiene unida. Así la dependencia y asimetría entre hijos y padres puede verse invertida cuando los primeros «crían» a los segundos en su vejez. Las relaciones no son concebidas como estables ni como algo dado. Si no existen vínculos de cuidado, las personas pueden querer marcharse.

Como mencioné en la introducción, varias etnografías de las tierras bajas sudamericanas resaltan cómo la comensalidad define las relaciones de familiarización de los parientes y la concepción de bienestar. Compartir la comida es una forma de crear vínculos de parentesco al hacer que las personas se acostumbren a vivir juntas y recuerden el cuidado recibido. Como menciona Scazzocchio, al preguntar sobre el término ayllu — difícil de definir, según la autora, debido a la variación de los significados dependiendo del contexto en que era usado- la respuesta que obtuvo fue que ayllu son «los que comen juntos en las fiestas» (1979, p. 83), refiriéndose a los grupos que se conforman a la hora de compartir los alimentos en cada celebración.

2 Como subrayan Gow (1991) y Belaúnde (2001) en su trabajo con los yine y los airo-pai, respectivamente, entre otros. Estas relaciones de cuidado no están exentas de asimetría, como señala Costa (2017) al enfatizar los vínculos de dependencia en la constitución del parentesco kanamari. 
Cuando las mujeres van a vivir con la familia de su esposo, sea en el mismo pueblo o en otro, las relaciones con sus parientes consanguíneos se mantienen mediante las visitas, en las que llevan regalos de la chacra, y a través las invitaciones para ayudar y compartir las cosechas. Este mujeo o intercambio entre parientes, no necesariamente de retribución inmediata, es importante para mantener la diversidad de cultivos. Son las mujeres las que seleccionan, guardan e intercambian las semillas y las relaciones de ellas con sus parientes de otros pueblos los que motivan este tipo de circulación (ver también Faiffer y Belaúnde, 2016). Cuando las hijas viven en las ciudades de Lamas o Tarapoto y tienen un ingreso monetario, también traen a casa otros presentes para sus madres, como azúcar, aceite, o productos para su cuidado personal, como jabones o champús. De esta manera, wiway (criar) pasa por una relación constante de compartir alimentos y otros cuidados corporales.

\subsection{La sal en el cuerpo y la socialidad humana}

Las montañas que, hoy en día, abarca el área de conservación regional Cordillera Escalera, además de incluir distintos lugares de caza, forman parte de los caminos kichwa que llevan a la mina de sal Tiraco. Esta mina, de sal blanca (yurak kachi), está cerca de otros dos domos, de sal roja (puka kachi) y sal morada (sani kachi). La mina de Tiraco tiene un ánima, madre o dueño (tres términos usados en el español lamista para referirse a esta relación de posesión y crianza), la Achkin Vieja (achkiy significa estornudar). Según don Ángel Sangama Amasifuén y su hijo Walter, de Alto Pucalpillo, la Achkin Vieja vivía antes en Tabalosos —otro de los lugares donde se concentró la población indígena desde la época colonial — donde también había una mina de sal. Pero la gente la rechazaba porque, al estornudar, salaba la comida con sus mocos. Un día, ella se enfadó y decidió partir lejos, hasta donde está actualmente, en Tiraco. Según don Walter:

Duro le han pegado. Y así cuando le han pegado, llorando llorando les ha dicho «nunca más me volverán a ver; no van a agarrar sal cerca; si quieren sal van a ir lejos caminando». Por eso se ha ido de Tabalosos, porque le han asqueado [...] Pero dice iba cayendo su polvo de la sal. Había a la vez un camino. Alguien le habrá perseguido, algún viejo. Y por mediante de ese polvo de esa sal, han llegado (Walter, comunicación personal, agosto de 2017).

Por su parte, en una conversación con doña Virginia Sangama Guerra, esta agregó que, después de ser expulsada de Tabalosos, la Achkin Vieja fue primero 
a Lamas, donde también había una mina de sal, pero donde también «le asquearon» y partió hacia Tiraco. El polvo que deja esta abuela recuerda al que dejan las personas en el trayecto de su vida y que, al fallecer, recogen al caminar como difuntos los lugares que han conocido.

La sal contribuye a la constitución de un cuerpo fuerte y sano. Según me indicaron en Alto Pucalpillo, bañarse en la quebrada Kachiyaku (agua salada), que nace en Tiraco, es bueno para no tener apostemas y curar la picazón, así como para sacar la saladera (mala suerte) y el cansancio del cuerpo. La mala suerte afecta la capacidad de cazar y criar alimentos. Esta puede ser consecuencia de no respetar las restricciones que los hombres y las mujeres deben cumplir, por ejemplo, durante el embarazo o después de la muerte de un pariente. Para combatirla, se debe realizar tratamientos con purgas (vegetales con poderes curativos, espíritus fuertes) y cumplir la dieta correspondiente. Aunque faltaría hacer un análisis más detallado sobre las distintas dietas, quiero llamar la atención sobre la abstinencia de sal en muchas de ellas. Incluso cuando una dieta no implica abstenerse por completo de comer sal, se recomienda disminuir al mínimo la cantidad. Ello vuelve el cuerpo más frío, lo que permite entrar en un estado de alteridad. Luego, para volver a la socialidad de la vida entre humanos, la dieta se corta empezando poco a poco a comer sal ${ }^{3}$.

La extracción y consumo de sal mineral de estas montañas comenzaron a ser controlados por el Estado peruano a finales del siglo XIX, a partir de la instauración del monopolio público de su comercialización y del establecimiento de impuestos. Sin embargo, según Rengifo (2009), desde la década de 1960 y la creación de la empresa de sal estatal, la prohibición del consumo de sal de las minas se volvió más rígida, incluyendo su confiscación por parte de la policía. Posteriormente, a partir de una serie de medidas sanitarias contra el cretinismo y el bocio - localmente llamado «coto», enfermedad que no era común en la época, según los testimonios que el autor cita-, se impuso el consumo de sal yodada. En este contexto, al control de la policía se añadió el del personal del Ministerio de Salud. Este entraba en las casas del Wayku a incinerar o botar bactericida en los kachimazos.

A pesar de ello, y de la consecutiva burocratización para acceder a la mina de sal de Tiraco — hoy en día, localizada dentro del área de conservación regional

La relación entre el consumo y abstinencia de sal, la transformación corporal y el movimiento entre la socialidad humana y los estados de alteridad se desarrollan con más detalle en Chaparro (2020). 
Cordillera Escalera, que les exige que pidan autorización para entrar- los lamista no han dejado de consumir esta sal. En el cotidiano, en Alto Pucalpillo, las personas compran sal yodada en las tiendas. No obstante, prefieren usar el kachimazo, que se encuentra en casi todas las cocinas, para la elaboración del takachu. Asimismo, esta es considerada más efectiva para la conservación de los alimentos que la sal industrial. Como afirma don Miguel Sangama Cachique, esta última «no entra en la carne, su encimita nomás y hace podrir la carne. ¿Pero a ver con la sal de Tiraque?» (Rengifo, 2009, p. 30; ver Wörrle, 1999, para ejemplos similares en otras partes de América Latina).

\subsection{Criar plantas, animales y lugares}

Por otro lado, como se puede observar en los diferentes ejemplos a continuación, todos los seres vivos, como la chacra y el monte, pasan por un proceso de crecimiento y regeneración similar que implica distintas relaciones de crianza mutua. De este modo, estas relaciones de familiarización por la consubstancialización y modelamiento de los cuerpos no se dan exclusivamente entre humanos: también incluyen a los animales, las plantas y otros seres con quienes los humanos entrelazan sus caminos, quienes se reconoce que son, en parte, sujetos ${ }^{4}$.

Estas relaciones pueden implicar distintos grados de asimetría, dependencia y cuidado. Entre los kichwa lamista, la crianza de los animales difiere de la crianza de los humanos en el sentido de que el ideal de cada especie se basa en diferentes nociones de fuerza, belleza y moralidad. Así, el modelamiento de cada uno de estos cuerpos-temperamentos es diferente. Por ejemplo, a los perros, en Alto Pucalpillo, les dan de comer alimentos grasosos (wira wira, como la pulpa del coco o el maní) para que sean bravos - pero cuidando que no se vuelvan demasiado bravos - y los hacen dietar para que ayuden a cazar. En cuanto a los caballos - cuya presencia era habitual antes de la proliferación de las motos y motocars-, les dan de comer inguiri (plátano verde cocido) y maíz, alimentos

4 La literatura antropológica ha desarrollado una amplia reflexión sobre las distintas dimensiones de estas relaciones en el caso de otros pueblos indígenas sudamericanos. Ver, por ejemplo, Fausto (2008) sobre la relación de predación familiarizante con los animales de caza a partir de su trabajo con Parakanã, Costa (2017) sobre los paralelos entre las relaciones de parentesco entre humanos y con los animales de estimación, y Shiratori (2019) o Lima (2017) sobre las relaciones de crianza con las plantas cultivadas entre los jamamadi y los krahô, respectivamente, entre otros. Desde esta reflexión, Fausto (2002) recalca cómo toda relación de predación familiarizante implica la distinción entre la parte-sujeto y la parte-objeto del otro, vinculada también con el riesgo de contrapredación. 
duros, para que sean fuertes. Ello lleva a pensar nuevamente en cómo las formas de los seres son transferidas mediante la ingestión.

Según los saberes compartidos por las personas de Alto Pucalpillo, los animales del monte — criados por el supay o shapingo — también pueden familiarizarse a los humanos a través de las dietas de estos últimos. Como afirma don Purificación Cachique Tuanama, «cuando tu cuerpo es curado, los animales son como tus hermanos, hasta tu tambo se van, en un árbol están cantando, se acercan» (en Panduro y Rengifo, 2001, p. 126). En este caso, el «como» también nos recuerda que asemejarse no implica equiparase. También se dice que las purgas que toman los montaraces para curarse -noción usada para referirse a la producción de efectos en el cuerpo, más allá de que sean positivos o negativosamansan a los animales. Asimismo, a estos se les convida sal, dejándola en las colpas — donde los animales del monte beben y se bañan — y se siembran frutales en los caminos para que coman y así se acostumbren a volver al mismo lugar. En este sentido, dicha relación no pasa por la domesticación o control de impulsos naturales como forma de socialización, sino por la implicación humana para establecer las condiciones de crecimiento, ${ }^{5}$ lo que incluye la crianza centrada en el dar de comer para que los otros vuelvan o quieran quedarse, tomando en cuenta sus gustos. Esto implica también aplacar el potencial agresivo y amenazante. Esta distinción entre amansar o acostumbrar, en el sentido en que los utilizan los lamista, y domesticar se condice con la que menciona Carneiro da Cunha entre taming y domestication (2020, p. 174).

En las comunidades kichwa lamista, la relación con los ojos de agua implica una crianza mutua. Donde no hay servicio de agua entubada, se dice que estos crían a los humanos y animales al proporcionarles el agua para beber a humanos y animales, para hacer chicha, cocinar, lavar la ropa y bañarse. También son lugares de encuentro para las mujeres y hábitat de ánimas fuertes. Estos manantiales o pukyus son sembrados y criados. Para ello, se debe traer el agua de otro lugar, que luego se seca, a la medianoche. Según don Ramón Amasifuen Guerra, el agua se lleva en un fruto llamado huingo, al que se le hace un pequeño agujero en el medio cuando está verde, para que el agua pueda gotear durante el camino hasta donde va a ser sembrada. Algunos dicen que la persona tiene que ir sola, otros afirman que tiene que ser una niña, y otros, que tienen que ser un hombre y una mujer desnudos, en la noche, cuando nadie los ve.

Como señala Ingold (2002) a partir de una reflexión sobre distintos pueblos cazadoresrecolectores. 
Alrededor de los ojos de agua de Alto Pucalpillo, sus criadores siembran distintas variedades de palmeras, plantas y árboles como, aguaje, ojé, polponta, shapaja, pijuayo, ishanga, yakusisa, yakuwitina, patquina y renaco. Estos tipos de vegetación ayudan a criar el agua, pero no necesariamente la engendran. Es posible que estos estuvieran antes en el lugar y que el agua no brotara de la tierra. En estos casos es necesaria la intervención humana, como aclaró don Juan Pablo Cachique Sangama, al contar cómo su padre, don Purificación Cachique Tuanama, sembró su pukyu:

Cuando ha sembrado, al año, ha empezado a hacerse húmedo. Bien húmedo. Pero no había agua. De ahí, me han dicho que aquí va a haber agua. Y habíamos hecho un pequeño pocito. $\mathrm{Y}$ al siguiente día cuando hemos venido hemos encontrado el pocito bien lleno. Entonces cuando ya había un poquito de agua, hicimos un pocito más grandecito. Seguía llenando. Y ahí, mi señora da a luz a mi primer hijito, a mi mayor. Ahí mi señora venía, sin enjuagar su boca, a exprimir su leche. Ahí tremendo ha aumentado esa agua. Y de esa manera esa agua hay de nosotros, no pierde (entrevista por la autora, en agosto de 2017).

O, como señala doña Dela Cruz Amasifuén Cachique:

Nosotros siempre le damos nuestra leche al pozo cuando quiere secar. Pero se le da en luna nueva para que no nos deje. Se va a la una de la mañana y de ahí se le exprime un poco de leche a nuestro pezón pidiendo que no se vaya al agua del puquial. Se va bien acompañado de nuestro marido, porque nos puede agarrar nomás su madre (en Rengifo, 2015, p. 26).

Así, al igual que con los animales del monte, se cría al agua para que continúe junto a ellos para que no se vaya o que desee volver. Igualmente, doña Dela Cruz Amasifuén explicita el carácter riesgoso o predatorio de estas relaciones. El amor de los otros seres puede ser dañino. Se dice que la madre del agua o los difuntos aman a la persona cuando la shingurea (le hace daño y la enferma) y se la lleva a su propio lugar, lejos de sus parientes. Frente a eso, se puede tener diferentes cuidados, como hacer morder un mazo de sal de la montaña a los recién nacidos para que no los ame el difunto o icarar a la madre del agua para amansarla.

Por su parte, la relación entre los humanos, la chacra y el monte implica también diferentes relaciones de crianza mutua para su regeneración. Los lamista diferencian entre varios tipos de monte, utilizando los mismos términos que usan para referirse al ciclo de vida humano: llullu purma, tierra en descanso tierna, bebé o no madura, que puede entenderse como el bosque que recién comienza a 
regenerarse; wayna purma, tierra en descanso joven, entre los cinco y diez años aproximadamente; machu purma, tierra en descanso vieja, de más de quince años aproximadamente, y monte alto o machu sacha (monte viejo). Cuando se tumba el monte para hacer una chacra, este ciclo empieza nuevamente. En cada una de estas, se encuentran diferentes especies.

Uno de los puntos que quiero enfatizar es la diferencia entre entender y tomar decisiones sobre el suelo solo a partir de las propiedades medibles en un estudio de clasificación - como los que se usan para definir la capacidad de uso mayor en el proceso de titulación-, con entender el papel que cumple la tierra en un ciclo en donde todos los seres implicados están en constante proceso de regeneración (lo que no quiere decir que los kichwa no reconozcan diferentes tipos de suelos aptos para distintas actividades y cultivos). Así, en determinados lugares donde los estudios de suelos arrojan que estos no son aptos para la agricultura o agroforestería - pues desde esta forma de conocimiento los suelos amazónicos se conciben como pobres, ácidos y limitados para los cultivos orientados al mercado (Lyons, 2014)—, según los conocimientos de los kichwa sí se pueden realizar estas actividades de forma rotativa. De acuerdo con esta última visión, los nutrientes se obtienen de las cenizas que resultan de la quema - cuya intensidad es preciso controlar para que sea beneficiosa - y de la crianza de la diversidad de plantas y árboles. ${ }^{6}$ Esta forma de cultivo no requiere las mismas características de suelos que enfatizan los estudios mencionados para tener «aptitud agrícola», como la profundidad del suelo (Lyons, 2014), en tanto son las hojas caídas las que proveen los nutrientes o vitaminas - como dicen en las comunidades - que permiten producir en cantidad y diversidad por varios años (Marquardt, Milestad y Porro, 2013; Marquardt y Romero, 2015). Para ello, siembran árboles específicos, como la guaba o el rujindi, que tienen un buen follaje para nutrir la tierra. De esta forma, se cría la diversidad del monte para ayudar a la regeneración de la chacra. Así, mientras las decisiones sobre las actividades que se pueden realizar desde la legislación y gestión ambiental, se están tomando a partir de las características del suelo, los kichwa están pensando en la relación entre criar una buena purma para tener una buena chacra (Marquardt y Milestad Porro, 2013).

Estas relaciones de crianza no son estables en el tiempo. Así como Descola (1998) afirma que, en las cosmologías amazónicas, las diferencias entre humanos, plantas y animales son de grado, no de naturaleza, Ingold (2002) enfatiza — a partir

6 Ver también Carneiro da Cunha (2020) sobre la importancia de las técnicas para el manejo de purmas entre otros pueblos amazónicos. 
de una comparación entre nociones de crianza entre humanos, plantas y animales en distintos pueblos cazadores-recolectores - que las diferencias entre recolectar y cultivar plantas o cazar y criar animales son de grado más que de tipo. Se encuentran en la dimensión de la implicación humana en el establecimiento de las condiciones de crecimiento — que pueden cambiar en el tiempo-, al igual que en la crianza de los hijos. Así, este autor llama la atención sobre cómo las hierbas pueden transformarse en plantas cultivadas y los animales de crianza pueden volverse feroces.

Varios autores enfatizan cómo los kichwa lamista conciben el monte como una extensión de la chacra (ver también Scazzocchio, 1979; Panduro y Rengifo, 1993; Choba Choba, 2001a). Las diferencias dentro de este espectro se manifiestan en la fuerza y forma de las plantas. Un caso es el de las purgas o remedios, que son más potentes - tienen un ánima fuerte - cuando son criadas por el monte, fuera de la vista de los humanos, pero también pueden ser criadas por estos últimos. Otro ejemplo son los llaktinos, que son los cultivos que se dejan creciendo en las purmas para que rebroten con más vitalidad, o las plantas que cría el monte cuando alguna semilla crece en otro lugar, con la lluvia, fuera de tiempo. El monte también se adhiere a ellos — «les apega»—, por lo que crecen más pequeños en comparación a cuando son criados en las chacras, según afirman en Alto Pucalpillo. Pero el llaktino también puede volverse wiwa al ser criado por los humanos cuando estos lo cuidan, le ponen tierra, le dan apoyo para no torcerse (Choba Choba, 2001b, p. 21).

En la chacra o la huerta, el buen crecimiento de las plantas no depende solo de la tierra, del clima o del cuidado que las personas les dan: también depende del afecto que sienten por estas últimas, así como muestran Nuckolls y Swanson (2018) en su análisis lingüístico del uso del quichua en los ríos Pastaza y Napo de Ecuador. Estos autores enfatizan igualmente la concepción, entre esta población, de un conocimiento contextualizado que se resiste a la generalización desde un punto de vista neutral, que puede resultar riesgosa, en tanto las afirmaciones explicitan la perspectiva del enunciador y de los otros posibles implicados frente a la experiencia narrada. Así, doña Rita Amasifuén Guerra me explicó de la siguiente forma que los tomates de su huerta no crecían: «El tomate no me quiere. No es por la tierra, porque mira cómo a mi suegra sí le crece». Si no gustan de la persona que las cría, las plantas se secan. En esos casos, se puede curar el cuerpo tomando purgas y haciendo una dieta para familiarizarse con las plantas y sintonizar sus cuerpos. En Alto Pucalpillo dicen que las nuevas semillas - como las nueras - tienen que acostumbrarse a su nueva familia. Por eso, a veces las mujeres las siembran primero en la huerta, para probar cómo se adaptan a la tierra 
y a la mano de su criadora. En este sentido, acostumbrar pasa por reconocer los gustos del otro y alimentar el cariño, vinculado a compartir cuerpos semejantes.

El crecimiento de las familias humanas también se asemeja al de las plantas. Los kichwa lamista se comparan a sí mismos a los mallki de plátano, su alimento diario. Los mallki son los retoños que nacen del rizoma de la planta madre que, para poder crecer sin apegarse, se siembran en lugares más alejados. De la misma forma, los lamista pueden querer buscar un nuevo lugar para vivir por diferentes motivos, como el interés por buscar lugares con abundancia de animales para cazar, para la apertura de nuevas chacras, la ocurrencia de plagas o por conflictos entre familias o con invasores. Scazzocchio (1979) afirma que el término mallki puede utilizarse como sinónimo de ayllu, grupo de parentesco que, dependiendo del contexto, identifica a familias constituidas por relaciones de descendencia y afinidad, a los que comparten el mismo apellido, asociado a un barrio del Wayku, o a los kichwa lamista como un todo.

Para entender mejor la relación de los kichwa con los otros seres de su entorno también podemos retomar la noción de poda. A diferencia algunas perspectivas de conservación que consideran las actividades antrópicas como amenazas (como las que se mencionan en el siguiente acápite), los lamista hacen referencia a la acción de podar o ralear tanto en relación con las plantas o árboles, como con los animales y la sal, que están insertos en ciclos de regeneración. Los buenos resultados dependen de la relación con las ánimas - madres o dueños- del monte. Los montaraces saben que si el dueño de los animales (el shapingo o supay) no quiere o no te reconoce, no te muestra los animales. De forma similar, la madre o dueña de la sal — que, en el caso de la mina Tiraco, es la Achkin Vieja - llora cuando las personas desperdician la sal y las puede enfermar. Eso no quiere decir que todos sean respetuosos, pero existen nociones de respeto sobre las cuales se puede establecer un diálogo que no pase por imposiciones o por consultas que se hacen solo por cumplir con un requisito burocrático.

Estas nociones kichwa de crianza y poda dialogan con las reflexiones de otros estudios antropológicos o arqueológicos en otras partes de la Amazonía, que enfatizan el carácter antropogénico del bosque (ver Balée, 1989, 1999 y 2013; Magalhães, 2016). Estas destacan cómo los pueblos indígenas, a través de sus prácticas de cultivo y caza, han contribuido activamente a criar la diversidad del paisaje amazónico. Pero, a diferencia de otras sociedades, esta crianza de plantas y de animales no se restringe a la domesticación (Fausto y Neves, 2018): implica relaciones que pasan por el reconocimiento mutuo en tanto sujetos con deseos, gustos y voluntad propia. Esto se condice con las afirmaciones de los kichwa 
sobre cómo, si el dueño del monte no te conoce, no te muestra los animales. También con la intención de familiarizar a los animales para que se acerquen. Igual sucede en la chacra. Para este reconocimiento, es importante la preparación del cuerpo mediante las dietas y baños con plantas de distintos tipos que cambian los humores, olores y temperaturas corporales con el fin de que los animales o las plantas te quieran o se aproximen.

En estas relaciones, caminar tiene un papel importante. Es caminando como el montaraz se puede relacionar con los seres del monte: encontrar las plantas medicinales más potentes - con ánimas fuertes, que son las que cría el monte fuera de la vista de los humanos-, conocer a los animales (sus sonidos, caminos, dónde se bañan y toman agua, cómo se relacionan entre sí) y que sus dueños conozcan a los montaraces de vuelta, así como aprender a ubicarse por los cerros y quebradas. Como afirmó don Purificación Cachique en julio de 2017, cuando estábamos reunidos en Alto Pucalpillo planificando una salida para visitar el lugar donde había sido denunciados don Ramón y sus parientes utilizando las imágenes de Google Earth: «Carachupa [refiriéndose a una persona por su apodo] camina por tierra, no como los gringos por satelital. Los wawkis [hermanos] caminan por las purinas [caminos]». Así, el monte se conoce al recorrerlo. A estos caminos se suman los que conectan las distintas chacras que poseen los kichwa en diferentes pisos ecológicos. El territorio, en este sentido, no está pensado como polígonos que se dividen según categorías fijas, sino como redes de caminos que alimentan relaciones en movimiento. En estas, las personas, otros seres y lugares toman posiciones cambiantes (como con la conformación de nuevos pueblos o llaktas, que se siembran como nuevos mallkis de plátano, que al igual que los manantiales, se pueden sembrar en otro lugar), en tanto cada uno está en constante crecimiento y regeneración, procesos en los cuales los demás también influyen.

Este mapeo de relaciones de crianza muestra que los vínculos de parentesco entre humanos mantienen formas similares y se entrelazan con las relaciones de estos con los seres con los que conviven. Así, los humanos crían y son criados por las plantas, los animales y los ojos de agua. Esta noción de crianza mutua no se refiere al parentesco entendido como reproducción biológica o de líneas de descendencia a través de la alianza con afines, pero sí a la regeneración del tejido relacional, que pasa por reconocer al otro como sujeto y por saber y querer alimentar y cuidar sus cuerpos y afectos. La crianza mutua implica cierta voluntad del otro de querer criarse con uno en una relación en que las posiciones de cuidar y ser cuidado o de alimentar, ser alimentado y ser alimento no son estables ni exentas de tensiones ya que ser amado implica el riesgo de ser apropiado pro el otro. 


\subsection{El conocimiento como relación}

Para terminar, quisiera señalar la relación entre conocimiento, posesión y propiedad. En los ejemplos descritos en este acápite, la posesión en ningún caso es exclusiva. La crianza de la chacra implica la intervención de diferentes ánimas, madres o dueños. En el monte, incluso si el dueño de los animales es el supay o shapingo, las purinas o caminos, como lugares de caza, también son dominio de los montaraces. Así como las chacras y las purmas son de alguien -incluso si no tienen el título de propiedad a su nombre-, los caminos también son de alguien, de quien los conoce, y esta posesión es respetada. Según Scazzocchio, (1979, p. 140) algunas purinas (caminos) eran consideradas dominios de un yachak («el que sabe», que se puede traducir como chamán) cuando lograban amansar las ánimas que vivían allí y alejar, en sus visiones, los espíritus de los otros hombres con quienes competían, así como también amansaban al dueño del monte antes de abrir una chacra en un lugar nuevo. Hoy en día, los lamista también se refieren a los caminos de los montaraces como su dominio, su purina. Así, salvo los principales — como los que llevan a la mina de sal— cada familia posee sus propios caminos.

Entre los riesgos de caminar por una montaña que no se conoce está la posibilidad de perderse o pisar una trampa colocada por otra persona. El shapingo también puede poner pruebas a quien llega por primera vez y hacer que se enferme. El dueño del monte suelta a los animales cuando conoce a la persona, así como sus madres avisan a los montaraces cuando van a aparecer. Según don Edinson Cachique Sangama, la huangana hacía soñar a su tío, con quien él iba a montear desde joven, que estaba bailando con música y «ropa típica» cuando iba a presentarse. Así, es mediante este reconocimiento como semejantes, en tanto sujetos que pueden compartir aspectos de la socialidad de la gente, como las fiestas, como se establece la relación.

Las diferentes formas que pueden adoptar las relaciones entre criadores y criados se expresan en los modos de poseer y compartir los lugares. La arcilla para confeccionar las cerámicas, aunque se encuentre en la chacra de alguien, no se puede mezquinar (mishay). «Ese es del señorito su tierra», según afirma doña Albina Guerra, incorporando también al cristianismo en estas relaciones. Igualmente, la mina de sal Tiraco es compartida por los kichwa de Lamas y del Huallaga. La madre de esta mina, la Achkin Vieja, llora y, de cólera, hace llover, cuando estos desperdician la sal y dejan todo sucio. 
Al mismo tiempo, como notó Scazzocchio (1978) en su investigación, ante la expansión de un grupo sobre un área, los límites se definían por consenso o se mantenían como lugares compartidos. Actualmente, los kichwa definen del mismo modo los límites de sus títulos comunales. Este es el caso de un grupo de comunidades de Lamas y del río Huallaga que habían solicitado su titulación abarcando esta mina de sal. En tanto la forma de titulación comunal no reconoce derechos por pueblo, se han visto llevados a establecer linderos formales, aunque también han acordado que ello no impediría el tránsito ni la caza y recolección más allá de estas fronteras. No obstante, surgieron críticas de un grupo a otro por no compartir el cuidado de los sembríos que se habían dejado en estos caminos. Uno de los grupos había sembrado allí un mallki de plátano verde, como suelen hacer, en una visita anterior. Cuando regresaron, vieron que quienes habían comido los plátanos no lo habían podado y el monte le había apegado. Lo que generó molestia, en este caso, no fue el hecho de que lo hayan comido, sino la falta de cuidado, de forma similar a la Achkin Vieja. Es desde esta concepción de compartir y respetar que, en varias oportunidades, a los kichwa les llama la atención que, hoy en día, las áreas naturales protegidas restrinjan el acceso a las montañas. Por ello, describen a las entidades que las administran como mezquinas.

Como mencionan Brightman, Fausto y Grotti (2016), entre otros, la noción de propiedad tiene una historia propia. Nace con la teoría jurídica romana - base de los regímenes de propiedad modernos, que definen los modos de adquisición individual a partir de la ocupación de lo que no es de ningún hombre- y fue traída a este continente por la colonización. Sin embargo, existen otras nociones de posesión en las cuales los objetos, los seres y los saberes pueden tener dueños (Fausto, 2008, entre otros).

En Alto Pucalpillo, se dice que los conocimientos, los caminos y los ojos de agua son de alguien — cuidados o criados por alguien - , pero no son de propiedad individual. Pueden ser compartidos por varias personas y familias, humanas y no humanas, pero no son de propiedad comunal. Así, como afirman Brightman, Fausto y Grotti (2016) a partir de una comparación entre varios pueblos indígenas de la Amazonia, la posesión de los seres y objetos - como personificaciones de las relaciones de crianza e intercambio, que implican también la transmisión de conocimientos - crea vínculos entre todos los que contribuyen con su regeneración, conformando una red heterogénea que varía de forma dependiendo de las relaciones entre ellos. Como dice Gow, para el caso de los Yine, "[e] ach category of space [...] has the form of a community of beings related together as owners and owned» (1991, p. 80). En este sentido, el camino de las familias denunciadas 
y el de la mina de sal por la quebrada Kachiyaku vinculan a las familias de Alto Pucalpillo con las montañas de donde fueron expulsadas a partir de la creación del área de conservación Cordillera Escalera, donde, hoy en día, están pidiendo como su título comunal.

De esta manera, incluso si algunos sentidos de las relaciones de posesión se pierden cuando se traducen al régimen de propiedad, eso no quiere decir que estos no puedan convivir con ella, como demuestra el caso de los kichwa lamista que, en algunas comunidades, tienen títulos de propiedad individual sobre sus tierras. Igualmente, puede decirse que estos nuevos conocimientos se incorporan a las relaciones de crianza. Al mismo tiempo, la propiedad también puede ser modificada al entrar en este proceso. En el Perú, la forma de propiedad se ha transformado para crear la figura de comunidad nativa. Pese a las dificultades que plantea, esta ha permitido la reproducción de las relaciones de crianza mutua entre la tierra y las familias indígenas vinculadas con ella al protegerlas de las crecientes presiones externas. Igualmente, en tanto el derecho es dinámico, existe la posibilidad de plantear cambios con el fin de garantizar la autonomía de los pueblos indígenas y el cuidado de su hábitat (ver las reflexiones de García Hierro, 2004; Chirif y García Hierro, 2007). Sin embargo, este último tiene una connotación distinta de cómo se pone en práctica el cuidado del medio ambiente por los conservacionistas en San Martín. Dentro de las relaciones de crianza kichwa lamista, la regeneración de su hábitat —incluyendo a los distintos seres que viven en él— no puede desligarse del cuidado de sí mismos.

\section{LA RED DE CONSERVACIÓN DE LA REGIÓN VERDE}

\subsection{Representar, clasificar y gestionar el territorio}

Un hito importante del movimiento ambientalista en San Martín fue la lucha contra la explotación petrolera en el Lote 103, de más de 870000 hectáreas, que abarca la cadena de montañas que son la principal fuente de agua de la ciudad de Tarapoto y sus alrededores. Las comunidades kichwa participaron activamente en este proceso, tomando la iniciativa en las marchas que pedían la nulidad del lote petrolero. Para frenar el avance de las actividades de exploración de este lote, en 2005, se creó el Área de Conservación Regional Cordillera Escalera (ACR-CE) y dos años después se aprobó su primer plan maestro, ${ }^{7}$ elaborado con el apoyo

Aunque sin la aprobación de la autoridad nacional competente, como lo requería la Ley de Áreas Naturales Protegidas (Ley No26834). 
técnico de la organización no gubernamental (ONG) CEDISA. La paralización de las actividades petroleras se consolidó por decisión del Tribunal Constitucional frente a una acción de amparo presentada por sectores de la sociedad civil. No obstante, la creación del área y la aprobación del plan maestro no fueron consultadas a las comunidades kichwa y kanpu piyapi que habitan estas montañas. Además, los derechos de las comunidades todavía no tituladas y su relación con el territorio no fueron considerados en el instrumento de gestión (ver también Pérez, 2017; Chaparro y Valderrama, 2017). Por el contrario, los asentamientos y las actividades humanas de cualquier tipo fueron identificados como amenazas para la conservación del área (GRSM, 2007, p. 41-46), en concordancia con una línea de pensamiento de larga data que ha descalificado, a nivel global, la agricultura «de roza y quema», itinerante o rotativa como perjudicial para el desarrollo y el medio ambiente, sin reconocer el tipo de ciencia que implica y sus beneficios (ver Carneiro da Cunha, 2020). Fue en este contexto, como señalan Chaparro y Valderrama (2017), que moradores de dos comunidades kichwa - Alto Pucalpillo y Ankash Yaku de Achinamisa - fueron denunciados por deforestación al realizar labores agrícolas en estas tierras.

En paralelo, un grupo de ONG, con apoyo de instituciones de la cooperación internacional ${ }^{8}$ - a quienes luego se sumó el gobierno regional — promovieron una serie de medidas para incorporar un enfoque territorial en la gestión pública, disminuir las altas tasas de deforestación que habían generado las políticas anteriores de conexión vial y ampliación de la frontera agrícola, y mejorar los indicadores socioeconómicos (Villarán et al., 2011; Ballón y Glave, 2015; Bernaola, 2015). En 2007, el partido político Nueva Amazonía ganó las elecciones regionales con una campaña centrada en las cuestiones ambientales - expresada en las palabras de orden «San Martín, región verde», que luego se convirtieron en el eslogan del gobierno - y una propuesta de mayor autonomía frente al gobierno central que exaltaba la identidad regional. El presidente de este partido y varios de los técnicos que lo acompañaron en ese momento provenían de las ONG ambientalistas. En este contexto, en los espacios de diálogo con las organizaciones indígenas, se repetían continuamente afirmaciones del tipo «todos somos sanmartinenses», discurso que homogeneizaba a la población e invisibilizaba los derechos diferenciados.

La Agencia Alemana de Cooperación Internacional (GIZ, por sus siglas en alemán), el Banco Alemán de Desarrollo (KfW, por sus siglas en alemán) y la Agencia de Estados Unidos para el Desarrollo Internacional (USAID, por sus siglas en inglés). 
Las premisas que guiaron al gobierno regional de San Martín (GRSM) durante este periodo concibieron a la naturaleza, principalmente los bosques, como «ventaja natural» de la región (ProAmbiente, 2015, p. 9), ejes del desarrollo sostenible, al mismo tiempo que beneficiarios de este. Con el apoyo de algunas ONG, bancos y agencias de cooperación internacional, el GRSM promovió su reestructuración institucional. En 2007, se creó una oficina de vigilancia y fiscalización ambiental y, en 2010, se definieron las competencias de la Autoridad Regional Ambiental en el Reglamento de Organización y Funciones del GRSM. Con estas medidas, San Martín se convirtió en una referencia para la implementación de estrategias de mitigación y adaptación al cambio climático, como los proyectos de Reducción de Emisiones por Deforestación y Degradación Forestal (REDD+) y otros mecanismos de retribución de servicios ecosistémicos (Acevedo, 2013).

Al construir un enfoque de desarrollo territorial sostenible, el GRSM propuso integrar la premisa del desarrollo humano con la conservación de los recursos naturales. Para ello, resaltó la importancia de la generación de consensos y la participación de la población, a la cual se asignaron «obligaciones y nuevas responsabilidades sociales» (ver $\left.N^{\circ} 015-2012-G R S M / C R\right)$. En este sentido - como apunta Escobar (1998) para el caso colombiano - se reprodujo y actualizó el discurso de los ecologistas liberales que afirma que todos somos responsables del futuro de «nuestro planeta». Sin embargo, como se detalla a continuación, al mismo tiempo, un conocimiento técnico-científico, con sus nociones de imparcialidad y neutralidad, fue definido como la base para la toma de decisiones y se restringió la discusión a los aportes de especialistas, excluyendo otros modos de conocimiento, valores y experiencias de vida.

El primer paso en este proceso fue el ordenamiento territorial. Este fue promovido como un dispositivo para el desarrollo sostenible en los espacios de discusión internacional que buscaban definir los mejores mecanismos para la gestión eficiente de los recursos naturales. En las reuniones técnicas entre los países que suscribieron el Tratado de Cooperación Amazónica, los gobiernos establecieron criterios comunes para ordenar el uso de estos recursos e incorporaron la Zonificación Ecológica Económica (ZEE) como el instrumento central para sostener técnicamente la planificación territorial de la Amazonía.

En el Perú, el ordenamiento territorial fue promovido por algunos gobiernos regionales y actores de la sociedad civil frente a la resistencia de los sectores estatales y privados vinculados con las actividades extractivas. A partir de esta discusión, se aprobó progresivamente un marco normativo para incentivar y regular su implementación. En 1996, se aprobó la «Estrategia para la zonificación 
ecológica económica y monitoreo geográfico de la Amazonía peruana»; en 2001, se promulgó el Decreto Supremo No 045-2001-PCM, que declaró de interés nacional el ordenamiento territorial ambiental, y en 2004, se aprobó el Decreto Supremo $\mathrm{N}^{\circ}$ 087-2004-PCM, que reguló la ZEE y la definió como el instrumento de gestión que permite armonizar las intervenciones y las actividades económicas con las «potencialidades del territorio». No obstante, en los últimos años ha habido una tendencia inversa que debilitó el procedimiento9. San Martín fue la primera región que culminó la ZEE como parte de una estrategia mayor frente a la problemática regional de deforestación. Esta experiencia sirvió de ejemplo para elaborar la normativa nacional (Bernaola, 2015).

Según esta última, la ZEE consiste en un estudio técnico orientado a determinar las potencialidades y limitaciones de cada zona identificada en el territorio - interpretadas como sus vocaciones - y a definir alternativas de usos sostenibles en función de variables ambientales, económicas, socioculturales, institucionales y geopolíticas ${ }^{10}$. Con este objetivo, en 2002, el GRSM convocó a un grupo técnico responsable de capacitar a los especialistas, generar información y difundir los avances del proceso de zonificación. Este grupo estuvo conformado por entidades del gobierno regional, ONG, instituciones de investigación y de la cooperación internacional que, en la mayoría de los casos, tenían intereses afines - el cuidado del medio ambiente, el desarrollo sostenible y la gestión territorial—y estaban familiarizadas con el lenguaje especializado.

La ZEE en San Martín, aprobada en el 2006 (mediante Ordenanza Regional $N^{\circ}$ 012-2006-GRSM/CR), incluyó catorce estudios temáticos sobre las características biofísicas y los aspectos socioeconómicos de la región. ${ }^{11}$ Como resultado de ellos, se definió cuatro frentes económicos: el urbano, el extractivo, el agropecuario y el de conservación. Mientras se indica, en el texto, que los tres primeros no aprovechan el potencial del territorio regional, generan el deterioro ambiental y agudizan los problemas socioeconómicos, el de conservación se entiende como un frente emergente para un amplio espacio regional que sí aprovecha su potencial. A partir

9 En el 2014, la promulgación de la Ley No 30230 eliminó el carácter vinculante y participativo del ordenamiento territorial y disminuyó las competencias del Ministerio de Ambiente al condicionar la aprobación de la política nacional de ordenamiento territorial a la decisión del Consejo de Ministros.

10 Ver Decreto Supremo No 087-2004-PCM.

11 Que incluyen información sobre el clima, la geología, la geomorfología, la fisiografía, el suelo, la capacidad de uso mayo de la tierra, la vegetación, los tipos de bosques, el contexto histórico, el perfil demográfico, los flujos migratorios, las actividades económicas, la ocupación actual del espacio y la definición de frentes económicos, como se explica a continuación. 
de este diagnóstico, que implicó la definición de variables pensadas como formas de organizar la información a fin de conocer objetivamente el territorio, este se estrió en mapas -creando unidades biofísicas y socioeconómicas consideradas como relativamente homogéneas-y se asignó una actividad a cada polígono. A pesar de que en la presentación del documento de resumen, se define la ZEE como un «proceso de construcción social del territorio» flexible, dinámico y perfectible (GRSM, 2005, p. 6), en la práctica, ha funcionado — retomando las reflexiones de Acselrad sobre la implementación de la ZEE en Brasil-, como una «verdad ecológica del territorio» (2000, p.7). Esta ha producido efectos concretos en la vida de la población indígena al ser tomada coma sustento para la elaboración de políticas regionales y en tanto la concordancia con este instrumento pasó a ser un requisito para la aprobación de actos administrativos.

Así, a través de la ZEE, la «región verde» se constituyó midiendo el espacio para clasificarlo y creando segmentos rígidos e internamente homogéneos para distribuir la población y las actividades económicas: $14,87 \%$ del territorio regional para actividades productivas, $0,15 \%$ para el desarrollo urbano o industrial, $64,60 \%$ para la protección y conservación ecológica, 20,38\% para la recuperación de los ecosistemas degradados y el 0\% como zona de tratamiento especial (GRSM et al., 2005). En esta cuadrícula, la mayor parte de los territorios indígenas quedaron incluidos en las «zonas de protección y conservación»o en las «zonas de recuperación de ecosistemas».

El documento de la ZEE contiene poca información sobre los pueblos indígenas de la región, además de presentar datos contradictorios. En la parte referida al perfil demográfico, se menciona que la población indígena — en la que, al principio, solo se incluye a los awajun y los shawi o kanpu piyapi- se estima en «apenas 1500 habitantes» (GRSM et al., 2005, p. 46). Sin embargo, en la sección sobre la ocupación del espacio regional, se indica que la población kichwa - distribuida por toda la región - equivale a 50000 habitantes. Luego, se afirma que las «costumbres ancestrales» y los «relictos de esta etnia» están únicamente en siete comunidades nativas de la provincia de Lamas (GRSM et $a l ., 2005$, p. 55). El documento omitió que, cuando la ZEE fue aprobada, existían en la región catorce comunidades kichwa tituladas: nueve en la provincia de Lamas, cuatro en El Dorado y una en San Martín ${ }^{12}$. Además, como señalamos Chaparro y Valderrama (2017), la ZEE no incluyó ninguna información sobre las comunidades pendientes de reconocimiento y titulación, excluyéndolas como factor a ser considerado en la toma de decisiones.

12 Información pública de la Dirección Regional Agraria de San Martín (DRASAM). 
Figura 1. Mapa de la ZEE de San Martín

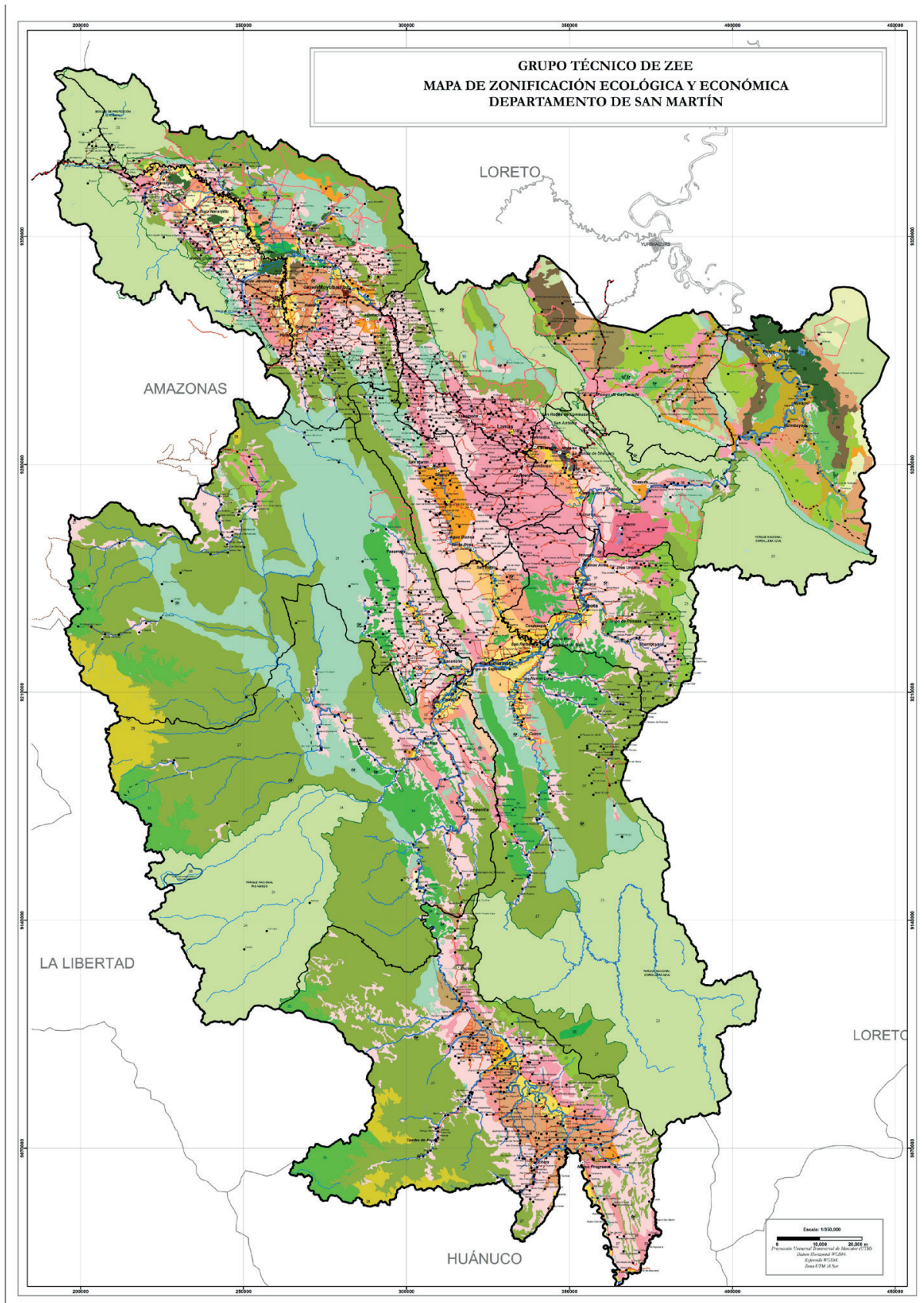




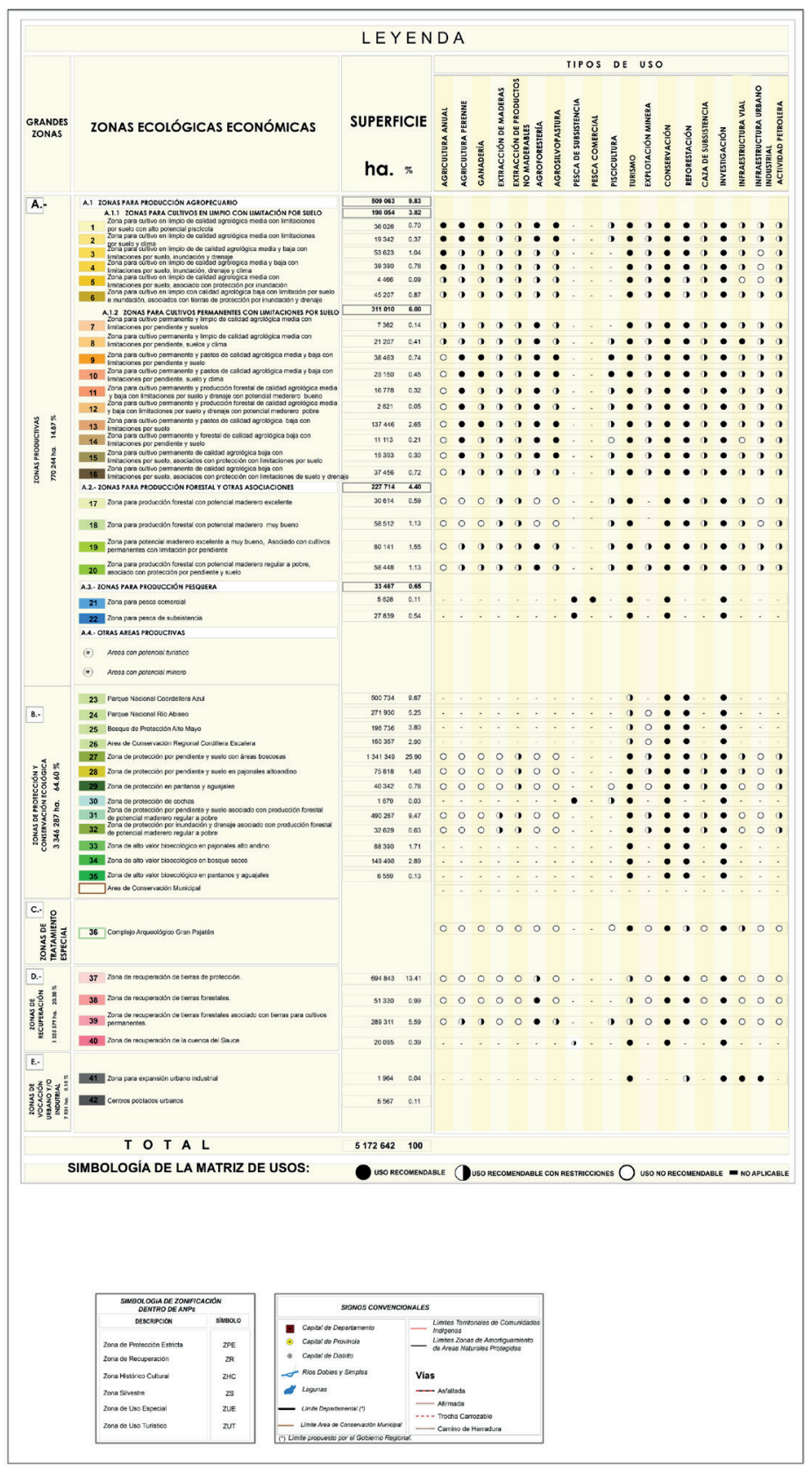

Fuente: GRSM (2005). Es posible descargar para observar mayores detalles. Recuperado de $<$ http://siar.regionsanmartin.gob.pe/mapas/mapa-zonificacion-ecologica-economica-departamento-san-martin>. Fecha de consulta 22 de junio de 2021. 
Cuando la ZEE fue reglamentada, en 2009, el uso de este instrumento se volvió obligatorio. La Autoridad Regional Ambiental determinó la necesidad de un informe de validez otorgado por esta institución para emitir actos administrativos relacionados con el uso y ocupación del espacio. Luego, utilizó este poder para tratar de condicionar la emisión de dicho informe para la aprobación de una escuela en la comunidad nativa de Puka Rumi al compromiso de no ampliar la frontera agrícola, sin considerar los factores que estaban generando la deforestación en la zona ni respetar su derecho a la educación.

Las organizaciones kichwa, awajun y kanpu piyapi reconocieron que la ZEE representaba un avance en términos del cuidado del medio ambiente. Sin embargo, expresaron preocupación porque su participación no fue efectiva y demandaron el cumplimiento de su derecho a la consulta previa, ya que esos instrumentos de gestión serían aplicados en sus territorios ${ }^{13}$. Ante ello, el Consejo Regional respondió que la ZEE es un estudio técnico-científico y que, como tal, no necesita someterse a consulta (Informe Legal N ${ }^{\circ}$ 083-2013-SCR-GRSM/ALE).

En el documento de la ZEE, el «frente de conservación» se describe como «legado de la economía territorial indígena» y como el espacio donde es posible aprovechar el capital natural de la región a partir de actividades como el ecoturismo, la bioinversión, la creación de áreas naturales protegidas y las actividades hidroenergéticas (GRSM et al., 2005, pp. 57-58), sin pensar en las actividades previamente realizadas por la población indígena. Esta imagen refleja el lugar muchas veces atribuido al «nativo ecológico» en el movimiento ambientalista a partir de su identificación como guardián de la biodiversidad, como afirman Ulloa (2001) y Escobar (2010) para el caso colombiano. Desde esta perspectiva de desarrollo sostenible, las ontologías indígenas suelen ser consideradas como un factor cultural, dimensión secundaria con relación a la eficiencia. En el caso de la elaboración de la ZEE en San Martín, la representación cartográfica excluyó a los territorios indígenas. Al mismo tiempo, los conocimientos y prácticas de estos pueblos no fueron entendidos en sus propios términos, sino resignificados para servir a los imperativos de la conservación.

En 2011, la Autoridad Regional Ambiental creó el Sistema Regional de Conservación. Para su implementación, se identificaron tres corredores de conservación que conectan las áreas naturales protegidas con las zonas categorizadas en la ZEE como zonas de conservación y recuperación de ecosistemas (SERNANP, 2014). En estos corredores, la Autoridad Regional Ambiental ha promovido

13 Declaración de Tarapoto. Gestión de los Territorios Integrales de los Pueblos Indígenas, 19 de noviembre de 2013. 
diversas modalidades de conservación: concesiones por cuarenta años (otorgadas a asociaciones de productores, comunidades, organizaciones indígenas y ONG a partir de la presentación de un expediente técnico), áreas de conservación privadas, áreas de conservación regional, zonas de conservación de conservación y recuperación de ecosistemas (ZOCRE, figura creada en San Martín a partir de la cual zonas de protección y conservación, según la ZEE, consideradas «áreas libres» han sido declaradas propiedad del gobierno regional) ${ }^{14}$ y la titulación de comunidades nativas. Pero, nuevamente, solo identificó a las comunidades cuyos territorios ya están saneados, lo que generó la superposición de las otras modalidades de conservación sobre territorios que comunidades kichwa están pidiendo en titulación, sin cumplir con la consulta previa.

En 2013, San Martín era la región del país con más porcentaje de hectáreas bajo concesiones de conservación con relación a su superficie total (CEPES, 2013). La ONG con mayor número de hectáreas bajo esta modalidad era Amazónicos por la Amazonía (AMPA), cuyos técnicos desempeñaron un papel importante en la elaboración de la ZEE. Según los informes de las instituciones involucradas (USAID, 2008; Cordero et al., 2014), en la concesión gestionada por AMPA y en tres de Pur Projet, se han implementado proyectos de REDD+ con el apoyo del GRSM y de distintas entidades de la cooperación internacional. Así, la formulación de las políticas de desarrollo sostenible ha implicado la concepción de una problemática ambiental desde una mirada sobre los territorios más allá de las soberanías nacionales, fortaleciendo la internacionalización de la gestión de los recursos naturales y la conversión de los bosques hábitat de los pueblos indígenas en «cuestiones globales» de importancia para la supervivencia de toda la humanidad (Sachs, 2000). De esta manera, estos bosques fueron incorporados dentro de la lógica del desarrollo sostenible y empezaron a ser considerados como reservas de carbono, mercancía insertada en las dinámicas del capital por medio del mecanismo de REDD $+{ }^{15}$.

14 Hasta junio de 2015, la Autoridad Regional Ambiental identificó 57 ZOCRE, de las cuales diecinueve fueron registradas como propiedad del GRSM y 38 mantenidas como propuestas.

15 Hay varias críticas y reformulaciones del mecanismo de REDD+. Algunas, dentro de la misma lógica del desarrollo sostenible, enfatizan la necesidad de no solo considerar los árboles en pie, sino de conservar los ecosistemas. Otras cuestionan el mecanismo por proponer una falsa solución a la crisis climática, al no evitar que los actores que contaminan lo sigan haciendo. Las organizaciones agrupadas en la Coordinación de las Organizaciones Indígenas de la Cuenca Amazónica propusieron una adecuación a partir del mecanismo REDD+ Indígena (RIA), que incluye una serie de condiciones, como el respeto a sus derechos territoriales, controlar la especulación y los intentos de venta de carbono que están presionando a las comunidades, incorporar la perspectiva cultural de la relación integral de esos pueblos con su entorno y dar prioridad al funcionamiento de fondos públicos, no al establecimiento de un mercado de carbono que sirva para compensar las emisiones industriales (AIDESEP, 2013). 


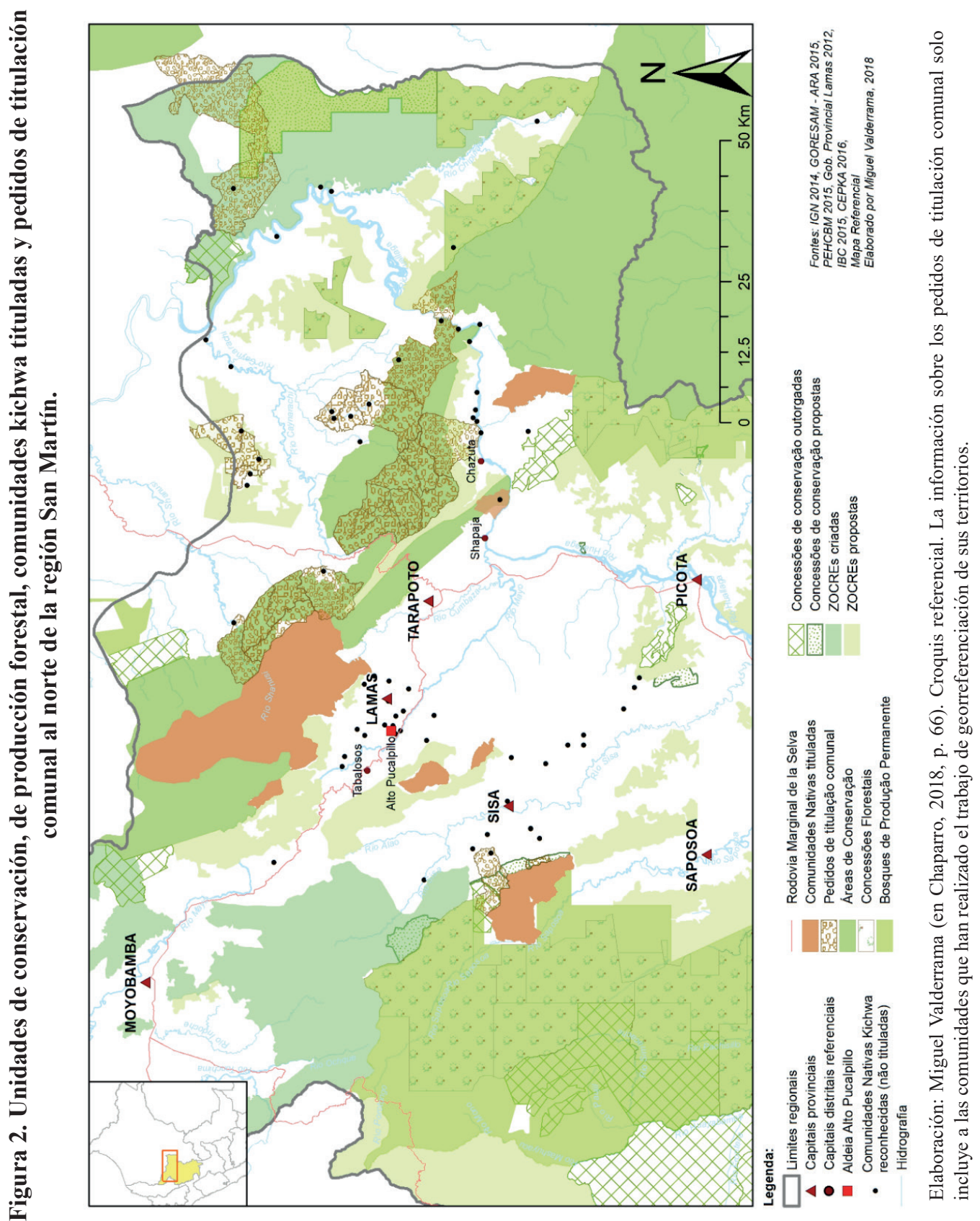


Al ser uno de los primeros países en formalizar su interés por estos mecanismos, el Banco Mundial eligió al Perú como país piloto para la preparación de una estrategia readiness y la implementación del programa nacional de REDD+, para el cual canalizó un financiamiento de más de 350 millones de dólares (ver Espinoza y Feather, 2011). A estos, se sumaron otros acuerdos y proyectos, como el del Banco Interamericano de Desarrollo (BID) y el de la Agencia de Cooperación Internacional de Japón. En este contexto y ante las políticas regionales descritas, San Martín fue identificado por el Ministerio del Ambiente como una de las regiones con mayores capacidades para recibir el apoyo de la cooperación internacional.

Como parte de este proceso, en 2009 se creó la Mesa REDD+ San Martín, donde participaron diversas instituciones. Para la elaboración de la estrategia regional de REDD+, las organizaciones indígenas fueron consideradas en las etapas de levantamiento de información y de fortalecimiento de capacidades, pero no en la elaboración de las propuestas ni en la retroalimentación, como señala Acevedo (2013). Esta estrategia identificó un conjunto de salvaguardias sociales y ambientales, dentro de las cuales se ha incluido el respeto a los derechos territoriales de los pueblos indígenas. Sin embargo, el nivel de avance de la titulación comunal ha sido significativamente menor que el del resto de modalidades de conservación mencionadas.

Las organizaciones indígenas que representan a las comunidades aún no tituladas han demandado el saneamiento de la propiedad de sus territorios antes de continuar con la implementación de mecanismos de REDD+. Sin embargo, existen varios proyectos REDD+ ya en marcha (Espinoza y Feather, 2011; Chaparro, 2018). Estos priorizan a las comunidades que ya cuentan con título, reproduciendo los patrones de exclusión de aquellas que aún no tienen seguridad jurídica sobre sus territorios.

Por otro lado, algunas organizaciones indígenas han recibido financiamiento —por ejemplo, de la FAO, canalizado por la ONG CEDISA — para implementar proyectos de manejo forestal comunitario. En estos proyectos, los indígenas se transforman en veedores forestales. Estos atraviesan un proceso de capacitación a partir del cual interiorizan el lenguaje de la conservación y de la gestión eficiente de los recursos naturales. Tanto ellos como los guardaparques de las áreas naturales protegidas — a veces, también, moradores de las comunidades nativas — forman parte de las técnicas de vigilancia del dispositivo de conservación. Ellos son los responsables de controlar la extracción de madera por terceros y actúan también como mecanismo de autovigilancia de las comunidades. En varios casos, este 
tipo de proyectos ha incorporado el uso de nuevas tecnologías para monitorear la cobertura boscosa, como imágenes satelitales o drones, a los que se refería, en el acápite anterior, don Purificación, al marcar la diferencia con la experiencia de caminar en el monte.

Para continuar con el proceso de ordenamiento territorial, en 2012, se aprobó la Política Territorial Regional (mediante la Ordenanza Regional No 015-2012GRSM/CR), donde se estableció como prioridad la implementación de los mecanismos de conservación. Dentro del cuadro jurídico de esta política, se mencionan distintas normas y acuerdos internacionales que enfatizan la necesidad de alcanzar un equilibrio entre el desarrollo económico y la conservación del medio ambiente ${ }^{16}$. No obstante, no se consideran los derechos particulares de los pueblos indígenas amparados en la Convención 169 de la OIT ni en la Declaración de las Naciones Unidas sobre los Derechos de los Pueblos Indígenas. La única mención a los pueblos indígenas es la promoción de su desarrollo integral definida como una política para las zonas identificadas en la ZEE como «de tratamiento especial», pero que no abarcan ningún territorio específico. Esta política considera la implementación de instrumentos de diagnóstico y planificación llamados «etnozonificación» y «planes de vida comunales», la titulación de comunidades nativas en función de la ZEE y la concesión de derechos a los pueblos indígenas, sin especificar cuáles. No obstante, la titulación tiene sus propios procedimientos que implican estudios a una escala menor que la ZEE regional.

Llama la atención, en este proceso, el papel de las ONG de San Martín en la canalización de proyectos de conservación y en la asesoría al gobierno regional. Las personas que dirigen estas instituciones - algunas de las cuales también han tenido cargos públicos o han estado vinculadas con los funcionarios por redes de parentesco y amistad - forman parte de una élite que busca exaltar la idea de una identidad regional amazónica — en contraposición a la población que proviene de los Andes, la más culpada por la deforestación - preocupada por el medio ambiente ${ }^{17}$.

16 Como el tratado de Cooperación Amazónica, la Declaración de Río sobre el Medio Ambiente y el Desarrollo, y la Convención sobre Biodiversidad Biológica.

17 En el sitio web de AMPA, la institución se describe de la siguiente forma: «Es interesante resaltar que, hacia el fin del siglo XX, la salvaguarda de la Amazonía era liderada por científicos u organizaciones foráneas; sin embargo paulatinamente los pobladores de la Amazonía andina hemos venido siendo más explícitos en nuestro discurso y actuando para revertir la creciente degradación de nuestra tierra. Así, en el año 2002 tres generaciones de amazónicos nos reunimos para formar un grupo de acción; constituyéndonos el año 2003 como una asociación civil 
El caso descrito nos lleva a pensar - como apunta Barroso (2008) sobre la actuación de la cooperación noruega junto a los pueblos indígenas - en el dispositivo del desarrollo no solo como una continuación de las relaciones de poder. En San Martín, las alianzas entre estos sectores y algunas organizaciones indígenas, mientras otras buscan proyectos centrados en la defensa de derechos, nos lleva a considerar como el cuadro de fuerzas no está constituido por dicotomías norte/sur o dominantes/dominados, sino por redes de agentes heterogéneos que comparten perspectivas e intereses. Sin embargo, haciendo un paralelo con las reflexiones de Escobar (2010) sobre el caso colombiano, esta red mantiene una forma jerárquica a través de un saber técnico-científico como mecanismo de poder.

\subsection{Cordillera Escalera y las comunidades nativas}

Por otro lado, la creación del Área de Conservación Regional «Cordillera Escalera» (ACR-CE), que abarca parte del territorio habitado por los kichwa y kampu piyapi, ha dificultado el proceso de titulación comunal. Durante varios años, a partir de su interpretación de la legislación nacional, los funcionarios del gobierno regional afirmaron que no era posible la superposición de los títulos comunales con esta área.

La falta de avances y el desinterés del gobierno regional llevaron a las organizaciones indígenas a convocar una movilización en junio de 2015 que contó con la participación de la mayor parte de las comunidades de la región. Las presiones ejercidas, así como las nuevas posibilidades de presupuesto, motivaron al gobierno regional a dar los primeros pasos para la titulación colectiva. Diez comunidades comenzaron el proceso en ese momento - cuatro dentro del ACR-CE- y se elaboró un cronograma para la titulación de las comunidades pendientes. Este número se amplió por el inicio de tres proyectos implementados en la región con financiamiento de organismos internacionales y gobiernos extranjeros, que incluyeron rubros para la titulación comunal debido a la incidencia de las organizaciones indígenas, negociados como parte de los acuerdos sobre la reducción de emisiones de carbono a nivel global. ${ }^{18}$

sin fines de lucro». Recuperado de <http://ampaperu.info/quienes-somos/nuestra-historia/>, fecha de consulta: 7 de abril de 2017.

18 Los proyectos que se implementaron en San Martín son el Mecanismo Dedicado Específico para pueblos indígenas (MDE Saweto Perú), que proviene del Programa de Inversión Forestal (FIP), financiado por el Banco Mundial; la Declaración Conjunta de Intención, acuerdo voluntario de cooperación firmado entre los Gobiernos de Perú, Noruega y Alemania; y el Proyecto de 
No obstante, las metas de estos proyectos no se cumplieron por diferentes dificultades en los procesos de titulación para las que, en algunos casos, no existían mecanismos claros de solución, entre ellas: la superposición con títulos individuales de comuneros y no comuneros, con áreas naturales protegidas, con ZOCRE, con bosques de producción permanente, con concesiones forestales, discrepancias entre las comunidades sobre sus linderos y conflictos con invasores vinculados al tráfico de tierra o madera. Estos últimos casos han sido denunciados por las comunidades, pero no han sido atendidos por la fiscalías respectivas (ver Pérez, 2021).

Así, después de dieciséis años de no haberse titulado ninguna comunidad nativa en la región, entre el 2016 e inicios del 2021, se titularon nueve, sumando un total de 38 comunidades tituladas de las 111 reconocidas, a las que se pueden agregar otras diez que han solicitado su reconocimiento. De estas, solo el territorio de una coincide con el del ACR-CE, de Nuevo Lamas de Shapaja, de la cual 98\% del título fue adjudicado bajo un contrato de cesión en uso, como se explica posteriormente. Debido a los problemas que presenta esta figura (identificados en Chirif y García Hierro, 2007 y García Hierro y Surrallés, 2009), la comunidad y su organización representativa -el Consejo Étnico de Pueblos Kichwa de la Amazonía (CEPKA)presentaron una acción de amparo (ver los argumentos legales en Ruiz, 2014) que fue desestimada en segunda instancia. A junio de 2021, esperaban una respuesta al recurso de agravio constitucional presentado en el Tribunal Constitucional.

En los últimos años, han surgido nuevas barreras para la titulación comunal en territorios coincidentes con el ACR-CE. A finales del 2019, el Ministerio de Agricultura aprobó la Resolución Ministerial N 443-2019-MINAGRI que, en su artículo 6.6.6 inciso b), prescribe que, en casos de superposición con áreas naturales protegidas, se procederá a la demarcación solo en aquellas comunidades nativas que hayan sido reconocidas formalmente con fecha anterior al establecimiento del área natural. Esta resolución fue aprobada sin consulta previa y, según Gavancho, Sangama y Ruiz (2020), desconoce el Convenio 169 de la OIT y el artículo 89 de la Constitución Política del Perú, por lo que CEPKA presentó una demanda de acción popular en julio del 2020. Asimismo, la Autoridad Regional Ambiental declaró improcedente la emisión de los contratos de cesión en uso de las comunidades que ya habían avanzado con los procedimientos respectivos como parte de los proyectos con financiamiento internacional (ver Oficio $\mathrm{N}^{\circ}$ 287-2020-GRSM/ARA/DEACRN).

Catastro, Titulación y Registro de Tierras Rurales en el Perú, Tercera Etapa (PTRT3) financiado con fondos públicos y un préstamo del Banco Interamericano de Desarrollo. 
Por otro lado, la segunda y última versión del plan maestro del ACR-CE fue aprobada en agosto de 2018, también sin realizar la consulta previa, con muchas demoras en tanto la versión anterior iba de 2007 a 2011. En la zonificación de esta versión, se han identificado algunas «zonas de uso especial», categoría que reconoce las actividades tradicionales de la población indígena. Sin embargo, estas no incluyen las tierras cultivadas o en barbecho (purmas) de todas las comunidades. Por ejemplo, las de Ankash Yaku de Achinamisa — por las cuales los funcionarios del Proyecto Huallaga presentaron denuncias por deforestación-, en esta versión de la zonificación se clasifican como "zonas de recuperación» y las de Alto Pucalpillo, como «zonas silvestres». Así, estos instrumentos de gestión no solo actúan midiendo y cuadriculando el espacio: también trazan líneas que dividen lo legal de lo ilegal, al mismo tiempo que formulan las técnicas para su control a partir de un movimiento de despolitización de la naturaleza.

Entre otros datos, estos argumentos toman en cuenta estudios de suelo utilizados para definir su «vocación» de forma similar que, en el proceso de titulación de comunidades nativas, se identifican las tierras con aptitud agrícola — que son dadas en propiedad - y las que son de aptitud forestal o de conservación - que son dadas bajo contrato de cesión en uso- . Las primeras son la minoría, en tanto — según esta forma de conocimiento - los suelos amazónicos se conciben como pobres, ácidos y limitados para los cultivos orientados al mercado. Así, se asocia cada lugar a una sola aptitud, como característica fija (ver Lyons 2014, para una reflexión similar sobre el caso colombiano). Por ello, Nuevo Lamas de Shapaja, la primera y única (hasta mediados del 2021) comunidad titulada en el mismo territorio que el ACR-CE, en 2016, recibió el 98\% de su territorio bajo un contrato de cesión en uso. A esto se sumó que, en este contrato, el administrador del área impuso una serie de condiciones que vulneran los derechos de los pueblos indígenas establecidos en la legislación nacional e internacional. Entre ellas, la obligación de solicitar autorización de la jefatura del área cuando quisieran extraer madera así sea para su propio uso y la prohibición de hacer chacras en las purmas (tierras en descanso) de más de seis años, truncando el ciclo de regeneración de la tierra para la crianza de alimentos.

Además de tener que lidiar con la criminalización de sus actividades, las comunidades afrontan la burocratización que les quieren imponer para caminar en esas montañas. La jefatura del ACR-CE les exige que pidan autorización haciendo llegar un documento cada vez que quieran ir a cazar y amenazó a la comunidad de Mishki Yakillu, en 2016, con «proceder conforme a ley» solo por construir un tambo (pequeña cabaña) para poder resguardarse en sus caminos (ver carta en Ruiz y Sangama, 2018). 
Por otro lado, es posible observar cómo el proceso de elaboración e implementación de las políticas de conservación ha constituido una verdad que coloca a los territorios y pueblos indígenas en un lugar ambiguo dentro del proyecto de construcción de la «región verde». En este caso, las áreas de protección son consideradas su legado, pero sus prácticas son vistas como amenazas. Las resistencias del gobierno regional frente al reconocimiento y titulación de los territorios indígenas en comparación con el avance de las otras estrategias de conservación muestran que el núcleo del debate no es solo cómo se construye el territorio regional a partir de la ZEE y de las políticas de desarrollo sostenible — proceso del cual los pueblos indígenas fueron excluidos-, sino también cómo se constituyen las comunidades nativas como sujetos de las políticas regionales.

Así, el dispositivo del desarrollo sostenible está produciendo a las comunidades nativas como sujetos de derecho condicionados a los objetivos de la conservación. Mientras su territorio es valorado por los servicios ecosistémicos que ofrecen, para hacer valer sus derechos, las comunidades deben comportarse como el «nativo ecológico» al que, como afirma Ulloa (2001) para el caso colombiano, se atribuye la responsabilidad histórica de proteger los bosques - de los que se convierten en guardianes- y mantener la biodiversidad ${ }^{19}$. Deben constituirse, retomando a Foucault y su reflexión sobre las tecnologías del yo (1999b), como sujetos útiles. No son tratados como sujetos de derechos en sí mismos, como demuestra el caso de la comunidad de Puka Rumi, donde la Autoridad Regional Ambiental quiso condicionar la aprobación de una escuela a la no ampliación de la frontera agrícola. Por eso, cuando los indígenas no actúan de acuerdo con esta racionalidad, son desterrados fuera de las fronteras de la legalidad, denunciados, y la apropiación de sus territorios está justificada por el bien mayor del desarrollo sostenible. Estas técnicas de gobierno implican también un disciplinamiento de los cuerpos kichwa al restringir su caminar y las relaciones de crianza entre las personas y los lugares que este andar regenera.

19 Ver también la reflexión de Descola (1998) sobre la diferencia entre la concepción de la relación con los animales desde la cosmología de los pueblos indígenas amazónicos — partiendo desde los achuar - y la de los movimientos ecologistas. Mientras los primeros conciben la similitud con los animales por la humanidad compartida en tanto condición que define a las personas morales y socialmente autónomas, no como sujetos de derecho tutelado, los segundos postulan la defensa de los animales por sus rasgos similares a los humanos como especie y mantienen a la sociedad — separada de la naturaleza - como fuente de derechos, que condena toda forma de violencia, administrada por los humanos. Para el autor, esto lleva a que las alianzas establecidas en convergencias superficiales puedan culminar en malentendidos. 


\section{REFLEXIONES FINALES}

A lo largo de este artículo he delineado dos redes — no desconectadas- que se distinguen entre sí por estar constituidas por diferentes tipos de relaciones. Por un lado, el entrelazamiento entre humanos, plantas, animales y otros seres con lo que los kichwa se vinculan, que asumen posiciones cambiantes de (co)criadores y criados. En esta, vivir juntos pasa por reconocerse como sujetos con agencia y voluntad, conocer los gustos de los otros, alimentar vínculos afectivos y manejar los riesgos potenciales que implican, compartir cuerpos semejantes (sin llegar a ser iguales), mantener los ciclos de regeneración y el tejido de caminos que resiste a la sedentarización. Por el otro, está el entramado entre los actores que participan en la conservación de la «región verde» y los recursos naturales que estos gestionan. En esta, el territorio se constituye como una realidad objetiva de la cual se puede extraer la verdad, representada en mapas que demarcan fronteras en el espacio y entre lo legal y lo ilegal. En función de un conocimiento técnico-científico que se concibe como neutral, se asignan polígonos fijos a cada actividad, al mismo tiempo que estas se burocratizan como parte de las técnicas para controlarlas. Dentro de este entramado, los indígenas ocupan una posición marginal y los derechos de las comunidades nativas, en la práctica, se condicionan a su papel como «guardianes de la naturaleza». En este sentido, el reconocimiento como sujeto en las relaciones de crianza no es el mismo reconocimiento jurídico que el que está otorgando el GRSM a las comunidades nativas, porque, en este último, su condición como sujeto de derecho está condicionada a lo que se considera un bien mayor que fue construido sin ellos.

A veces parece que las políticas regionales y los mecanismos de conservación quisieran que los kichwa se olvidaran de caminar o que no están pensando en la regeneración de las relaciones dentro de las que estos se crían. Las comunidades nativas actualmente están teniendo que lidiar tanto con la criminalización de sus actividades como con la burocracia para caminar en esas montañas. Esta forma de coacción restringe sus movimientos y la relación entre los kichwa y las montañas. De la misma forma, delimitar las actividades de las comunidades a partir de los resultados de los estudios de aptitud mayor del suelo interrumpe el ciclo de regeneración entre la chacra y el monte.

Con estas reflexiones, no quiero decir que la conservación como está pensada desde las políticas públicas o la cooperación internacional no pueda coexistir con las prácticas Kichwa de crianza mutua, sino enfatizar que ambas consideran diferentes nociones de cuidado, como pueden haber muchas otras, para no caer 
en dualismos. Para concluir, retomo la reflexión de Bruce Albert a partir de sus conversaciones con Davi Kopenawa, sobre cómo la comunicación y política interétnica son un campo de producción de «fórmulas semánticas de medio termo, cuja dialéctica al mismo tiempo contorna y reafirma las incompatibilidades simbólicas» (2002, p. 219, traducido por la autora), en un proceso en el que tanto las categorías indígenas como no indígenas son afectadas. Propongo retomar la importancia dada por los kichwa a la alimentación como modo de familiarización que permite vivir juntos, sin necesariamente volvernos iguales, para pensar en la posibilidad de una coexistencia nutritiva. Con ello, me distancio de los caminos que apuestan por negociar acuerdos que tengan como resultado una tercera noción consensuada, para optar por la defensa del mantenimiento de diferencias en las que las partes se abren a aprender y ser transformadas por el otro. Así como los kichwa y otros pueblos indígenas reconocen e incorporan tecnologías ajenas en su relación con el monte (como el uso de drones), el «cuidado de los bosques» que se defiende desde las ciudades - que enfatiza al bosque como un hábitat del que el ser humano se beneficia, como por los servicios ecosistémicos, pero del que no forma parte-, puede incorporar el cuidado de todos los seres implicados en estas relaciones.

\section{REFERENCIAS BIBLIOGRÁFICAS}

Acevedo, Paula (2013). Análisis sobre afectación de derechos de pueblos indígenas en los conflictos vinculados a REDD en la región San Martín. Lima: GIZ, AIDESEP.

Acselrad, Henri (2000). O zoneamento ecológico-econômico e a multiplicidade de ordens socioambientais na Amazônia. Novos cadernos naea, 3(2), 5-15. https:// doi.org/10.5801/ncn.v3i2.32.

Albert, Bruce (2002). O ouro canibal e a queda do céu: uma crítica xamânica da economia política da natureza. En Bruce Albert y Alcida Ramos (orgs.) Pacificando o branco: cosmologias do contato no norte-Amazonico (pp. 199-229). Marseille: IRD Éditions.

Albert, Bruce.y Le Tourneau, François-Michel (2007). Ethnogeography and resource use among the Yanomami: toward a model of «reticular space». Current Anthropology, 48(4), 584-592. https://doi.org/10.1086/519914

Asociación Interétnica de Desarrollo de la Selva Peruana (2013). Construyendo REDD+ indígena. Adecuación intercultural del REDD+ Perú a los derechos territoriales y colectivos de los pueblos indígenas. Lima: AIDESEP, GIZ. 
Balée, William (1989). The culture of Amazonian forests. En Darrell Posey y William Balée (orgs.), Resource management in amazonia: indigenous and folk strategies (pp. 1-21). New York: New York Botanical Garden.

Balée, William (1999). Footprints of the forest: ka'apor ethnobotany - the historical ecology of plant utilization by an amazonian people. New York: Columbia University Press.

Balée, William (2013). Cultural forests of the amazon: a historical ecology of people and their landscapes. Tuscaloosa: University of Alabama Press.

Ballón, Eduardo y Glave, Marisa (2015). San Martín: un viaje a la otra orilla. Lima: Grupo Propuesta Ciudadana.

Barroso, Maria (2008) Fronteiras étnicas, fronteiras de estado e imaginação da nação: um estudo sobre a cooperação internacional norueguesa junto aos povos indigenas. 366 f. Tese (doutorado em Antropologia Social) - Museu Nacional, programa de pós-graduação em Antropologia Social da Universidade Federal do Rio de Janeiro (UFRJ), Rio de Janeiro.

Belaúnde, Luisa Elvira (2001). Viviendo bien: género y fertilidad entre los Airo-Pai de la Amazonía peruana. Lima: Centro Amazónico de Antropología y Aplicación Práctica.

Bernaola, Diana (2015). Gobernanza en los procesos de ordenamiento territorial en la Amazonía peruana: las experiencias de San Martín y Loreto. Lima: Derecho, Ambiente y Recursos Naturales.

Brightman, Marc; Fausto, Carlos y Grotti, Vanessa. (2016). Introduction. Altering ownership in Amazonia. En Marc Brightman, Carlos Fausto y Vanessa Grotti (eds.), Ownership and nurture. Studies in native Amazonian property relations (pp. 1-35). New York/Oxford: Berghahn Books.

Carneiro da Cunha, Manuela. Antidomestication in the Amazon: swidden and its foes. En Geoffrey Lloyd y Aparecida Vilaça (eds.), Science in the forest, science in the past (pp. 171-190). Chigado: HAU Books.

Centro Peruano De Estudios Sociales - CEPES (2013). Conservación y ecoturismo. ¿Protección de los recursos naturales o herramienta para el acaparamiento? Boletín Tierra y Derechos, 3(8), 1-4.

Chaparro, Anahí (2018). Caminos de crianza Kichwa Lamista: relaciones entre personas y lugares de Alto Pucalpillo (Disertación de Maestría). Universidad Federal Fluminense, Niterói, Brasil (Versión en español traducida por la autora).

Chaparro, A (2021). Territorio habitado y territorio como derecho: reflexiones desde el caminar kichwa lamista. Revista de Antropología y Sociología: Virajes, 23(1), 118-147. https://doi.org/10.17151/rasv.2021.23.1.6 
Chaparro, Anahí y Valderrama, Miguel (2017). Políticas de conservação e direitos territoriais dos povos indígenas: o caso da região San Martín, Perú. Habitus, 15(1), 73-92. https://doi.org/10.18224/hab.v15i1.5901

Chirif, Alberto y García-Hierro, Pedro (2007). Marcando territorio: progresos y limitaciones de la titulación de territorios indígenas en la Amazonía. Copenhage: IWGIA, Grupo Internacional de Trabajo sobre Asuntos Indígenas.

Choba Choba (2001a). Crianza del monte en los Quechua-Lamas. Lima: Pratec.

Choba Choba (2001b). Organicidad quechua lamista en la crianza de la diversidad agrícola. «urdiendo la vida chacarera». En Pratec (ed.), Comunidad y biodiversidad. El ayllu y su organicidad en la crianza de la diversidad en la chacra (pp. 213-223). Lima: Pratec.

Cordero, Doris; Suárez de Freitas, Gustavo; Schneider, Claudio y Che-Piu, Hugo (2014) Informe país. Consideraciones para la distribución de beneficios REDD+en Perú. [s.1.]: The Forest People Dialogue.

Costa, Luiz (2017). The owners of kinship. Asymmetrical relations in indigenous Amazônia. Chicago: Hau Books.

Da Matta, Roberto (1976). Um mundo dividido: a estrutura social dos índios Apinayé. Rio de Janeiro: Vozes.

Das, Veena y Poole, Deborah (2008) El Estado y sus márgenes. Etnografías comparadas. Cuadernos de antropología social, 27, 19-52.

Descola, Philippe (1998). Estrutura ou Sentimento: a relação com o animal na Amazônia. Mana: Estudos de Antropologia Social, 4(1), 23-45.

Escobar, Arturo (2007 [1998]). La invención del tercer mundo. Construcción y deconstrucción del desarrollo. Caracas: Ministerio del Poder Popular para la Cultura.

Escobar, Arturo (2010) Territorios de diferencia: lugar, movimientos, vida, redes. Popayán: Envión.

Faiffer, Gladys y Belaúnde, Luisa Elvira (2016). Mujer, biodiversidad y seguridad alimentaria en las comunidades Kechua-Lamas. Lima: Waman Wasi, Pratec.

Fausto, Carlos (2002). Banquete de gente: comensalidade e canibalismo na Amazônia. Mana: Estudos de Antropologia Social, 8(2), 7-44.

Fausto, Carlos (2008). Donos demais: propriedade e maestria na Amazônia. Mana: Estudos de Antropologia Social, 14(2), 329-366.

Fausto, Carlos y Neves, Eduardo (2018). Was there ever a Neolithic in the Neotropics? Plant familiarization and biodiversity in the Amazon. Antiquity publications, 92(366), 1604-1618. 
Ferguson, James (2012). La maquinaria antipolítica. Desarrollo, despolitización y poder burocrático en Lesoto. En B. Pérez (ed.), Antropología y desarrollo. Discurso, práctica y actores (pp. 239-257). Madrid: La Catarata.

Foucault, Michel (1979). História da sexualidade I: a vontade de saber. Rio de Janeiro: Graal.

Foucault, Michel (1989). Vigiar e punir: nascimento da prisão. Petrópolis: Vozes.

García-Hierro, Pedro (2004). Territorios indígenas: tocando a las puertas del derecho. En A. Surrallés y P. García-Hierro (orgs.), Tierra adentro: territorio indígena y percepción del entorno (pp. 277-306). Copenhage: IWGIA.

García Hierro, Pedro y Surrallés, Alexandre (2009). Antropología de un derecho. Libre determinación territorial de los pueblos indígenas como derecho humano. Copenhague: IWGIA.

Gavancho, Cristina, Sangama, Marco y Ruiz, Juan Carlos (2020). CEPKA presenta demanda de acción popular contra R.M N 443-2019-MINAGRI aprobada sin consulta previa. Instituto de Defensa Legal. Recuperado de <https://www.idl. org.pe/cepka-presenta-demanda-de-accion-popular-contra-r-m-n-443-2019-minagri-aprobada-sin-consulta-previa/>

Gobierno Regional de San Martín (GRSM), Instituto de Investigadores de la Amazonía (IIAP) Peruana, Grupo Técnico de la ZEE San Martín (2005). Las potencialidades y limitaciones del departamento de San Martín. Propuesta de Zonificación Ecológica Económica como base para el ordenamiento territorial. S.1.: GRSM, IIAP, Grupo Técnico de la ZEE San Martín.

Gobierno Regional de San Martín (2007). Área de Conservación Regional Cordillera Escalera. Plan Maestro 2007-2011. Tarapoto: Gobierno Regional de San Martín.

Gow, Peter (1991). Of mixed blood: kinship and history in Peruvian Amazonia. Oxford: Clarendon Press.

Gow, Peter (1995). Land, people, and paper in western Amazonia. En E. Hirsch y M. O'Hanlon (orgs.), The anthropology of landscape. Perspectives on place and space (pp. 42-62). New York: Oxford University Press.

Ingold, Tim (2002). The perception of the environment: essays on livelihood, dwelling and skill. New York: Taylor \& Francis.

Kensinger, Kenneth M. (1995). How real people ought to live: the Cashinahua of eastern Peru. Prospects Heights: Waveland Press.

Lima, Ana Gabriela (2017). A Cultura da Batata Doce: cultivo, parentesco e ritual entre os Krahô. Mana: Estudos de Antropologia Social, 23(3), 455-490.

Lyons, Kristina (2014). Soil science, development, and the «elusive nature» of Colombia's amazonian plains. The Journal of Latin American and Caribbean Anthropology, 19(2), 212-236. 
Magalhães, Marcos (org.) (2016). Amazonia antropogénica. Belem: Museu Paraense Emílio Pereira.

Marquardt, Kristina; Milestad, Rebecka y Porro, Roberto. (2013). Farmers' perspectives on vital soil-related ecosystem services in intensive swidden farming systems in the Peruvian Amazon. Human Ecology, 41(1), 139-151.

Marquardt, Kristina. y Romero, Luis (2015). La agricultura indígena del kechwa-lamas y los servicios ecosistémicos. ¿Qué hay para aprender? Servindi (15 de noviembre). Recuperado de https://www.servindi.org/actualidad/142740

Mc Callum, Cecilia (1996). The body that knows: from cashinahua epistemology to a medical anthropology of lowland South America. Medical Anthropology Quarterly, 10(3), 347-372. https://doi.org/10.1525/maq.1996.10.3.02a00030.

Overing, Joanna (1977). Orientation for paper topics e comments. Simposio social time and social space in lowland South American societies. Actes du XLII Congrès International Des Américanistes, v. 2 (pp. 9-10 y 387-394). Paris: Societé Des Américanistes.

Overing, Joanna y Passes, Alan (2000). Introduction: conviviality and the opening up of amazonian anthropology. En Joanna Overing y Alan Passes (eds.), The anthropology of love and anger: the aesthetics of conviviality in native Amazonia (pp. 1-30). Londres: Routledge.

Panduro, Rider y Rengifo, Grimaldo (1993). Dinamicidad de la chacra. En Grimaldo Renfigo, Rider Panduro y Eduardo Grillo (eds.), Chacras y chacareros (pp. 19-139). Lima: Centro de Desarrollo e Investigación de la Selva Alta.

Panduro, Rider y Rengifo, Grimaldo (2001). Montes y montaraces: la visión del bosque en los Quechua-Lamas. Una aproximación. Lima: Pratec.

Rengifo, Grimaldo (2009). Los caminos de la sal: el regreso al territorio excluido. Efectos del fondo de iniciativas de afirmación cultural (FIAC) en la recuperación de los ámbitos de comunidad de los Quechua-Lamas. Lima: Pratec.

Rengifo, Grimaldo (2015). Según el gusto y las ganas. Lima: Pratec, Waman Wasi.

Ruiz, Juan Carlos (2014). Los contratos de "cesión en uso" forestales burlan derechos territoriales de comunidades. Servindi. Disponible en: https:/www.servindi.org/ actualidad/113577.

Ruiz Molleda, Juan Carlos y Sangama, Marco (2018) Insólito: Comunidades nativas de San Martín piden permiso para ingresar a su territorio ancestral. Servindi. Disponible en: https://www.servindi.org/actualidad-noticias/30/03/2018/insolito-comunidades-nativas-de-san-martin-piden-permiso-para

Sachs, Wolfgang. (2000). Meio ambiente. En W. Sachs (org.). Dicionário do desenvolvimento. Guia para o conhecimento como poder (pp. 117-131). Petrópolis - Río de Janeiro: Vozes. 
Scazzocchio, Françoise (1978). Curare kills, cures and binds: change and persistence of indian trade in response to the contact situation in the north-western montaña. Cambridge Anthropology, 4(3), 30-57.

Scazzocchio, Françoise (1979). Etnicity and boundary maintenance among Peruvian forest Quechua. Thesis (Ph.D.) - Cambridge. University Cambridge. Versión en español traducida por la autora.

Seeger, Anthony; Matta, Roberto. y Viveiros de Castro, Eduardo (1979). A construção da pessoa nas sociedades indígenas brasileiras. Boletim do museu nacional, 32, 2-19. Río de Janeiro.

Shiratori, Karen (2019). O olhar envenenado: a perspectiva das plantas e o xamanismo vegetal jamamadi. Mana: Estudos de Antropologia Social, 25(1), 159-188.

Surrallés, Alexandre y García-Hierro, Pedro (2004). Introducción. En Alexandre Surrallés y Pedro García-Hierro (orgs.), Tierra adentro: territorio indígena y percepción del entorno (pp. 9-22). Copenhage: IWGIA.

Tapullima, Leonardo (2012). Waynakuna-shipashkuna en la vivencia kechwa lamas. San Martín. Perú. En G. Rengifo y G. Faiffer (eds.), Concepciones de juventud en la visión andino amazónica (pp. 301-340). Lima: Pratec.

Ulloa, Astrid (2001). El nativo ecológico: movimientos indígenas y medio ambiente en Colombia. En M. Archila y M. Pardo (orgs.), Movimientos sociales, estado $y$ democracia en Colombia (pp. 286-320). Bogotá: ICANH-CES-Universidad Nacional.

USAID (2008). Peru alternative development program (PDA). Final report. Washington, D. C.: USAID.

Villarán, Fernando, Dávila, Miguel, Urday, Pedro, Sánchez, Benigno y Vargas, Rubén (2011). El modelo de desarrollo alternativo de la región san martín. Un estudio de caso de desarrollo económico local. Lima: UNODC.

Virtanen, Pirjo Kristiina (2016). Relational centers in the Amazonian landscape of movement. En N. Bon y J. Repič (orgs.), Moving places. Relations, return and belonging (pp. 126-147). New York: Berghahn Books.

Viveiros de Castro, Eduardo (1979). A fabricação do corpo na sociedade xinguana. Boletim do Museu Nacional, 32, 40-49.

Waman Wasi (2013). Para la continuidad de la buena vida (alli kawsana) desde la perspectiva del wayna-shipash Kechwa Lamas. San Martín-Perú. En Plataforma de Copartes de Terres des Hommes - Alemania (eds.), Sumaq kawsay. Vivir bonito (pp. 72-83). [s.1.]: Terres des Hommes - Alemania.

Wörrle, Bernhard (1999). De la cocina a la brujería: la sal entre indígenas y mestizos en América Latina. Quito: Abya Yala. 